\title{
ARTICLE
}

Received 10 Apr 2015 | Accepted 10 Sep 2015 | Published 20 Oct $2015 \quad$ DOl: 10.1038/ncomms9608 OPEN

\section{Follicular regulatory T cells impair follicular T helper cells in HIV and SIV infection}

Brodie Miles ${ }^{1}$, Shannon M. Miller ${ }^{1}$, Joy M. Folkvord ${ }^{1}$, Abigail Kimball ${ }^{1}$, Mastooreh Chamanian ${ }^{1}$, Amie L. Meditz ${ }^{1 \dagger}$, Tessa Arends ${ }^{1}$, Martin D. McCarter ${ }^{2}$, David N. Levy ${ }^{3}$, Eva G. Rakasz ${ }^{4}$ Pamela J. Skinner $^{5}$ \& Elizabeth Connick ${ }^{1}$

Human and simian immunodeficiency viruses (HIV and SIV) exploit follicular lymphoid regions by establishing high levels of viral replication and dysregulating humoral immunity. Follicular regulatory $T$ cells $\left(T_{F R}\right)$ are a recently characterized subset of lymphocytes that influence the germinal centre response through interactions with follicular helper $T$ cells $\left(T_{\mathrm{FH}}\right)$. Here, utilizing both human and rhesus macaque models, we show the impact of HIV and SIV infection on $T_{F R}$ number and function. We find that $T_{F R}$ proportionately and numerically expand during infection through mechanisms involving viral entry and replication, TGF- $\beta$ signalling, low apoptosis rates and the presence of regulatory dendritic cells. Further, $\mathrm{T}_{\mathrm{FR}}$ exhibit elevated regulatory phenotypes and impair $\mathrm{T}_{\mathrm{FH}}$ functions during HIV infection. Thus, $\mathrm{T}_{\mathrm{FR}}$ contribute to inefficient germinal centre responses and inhibit HIV and SIV clearance.

\footnotetext{
${ }^{1}$ Division of Infectious Diseases, Department of Medicine, Anschutz Medical Campus, University of Colorado, Aurora, Colorado 80045, USA. ${ }^{2}$ Department of Surgery, School of Medicine, Anschutz Medical Campus, University of Colorado, Aurora, Colorado 80045, USA. ${ }^{3}$ Department of Basic Science, New York University College of Dentistry, New York, New York 10010, USA. ${ }^{4}$ Department of Pathology and Laboratory Medicine, Wisconsin National Primate Research Center, University of Wisconsin-Madison, Madison, Wisconsin 53715, USA. ${ }^{5}$ Department of Veterinary and Biomedical Sciences, University of Minnesota, St. Paul, Minnesota 55108, USA. †Present address: Beacon Clinic, Boulder Community Hospital, Boulder, Colorado 80301, USA. Correspondence and requests for materials should be addressed to E.C. (email: Liz.Connick@ucdenver.edu).
} 
IV rapidly establishes a productive viral infection in secondary lymphoid tissues, which is maintained during chronic stages of disease ${ }^{1,2}$. During chronic HIV infection, viral replication is highly concentrated within B-cell follicles in follicular $\mathrm{T}$ helper cells $\left(\mathrm{T}_{\mathrm{FH}}\right)^{3-5} \cdot \mathrm{T}_{\mathrm{FH}}$ are crucial initiators of the germinal centre (GC) response ${ }^{6,7} \cdot \mathrm{T}_{\mathrm{FH}}$ have a distinct developmental pathway characterized by Bcl- 6 expression, which is dependent on inducible T-cell costimulator (ICOS) expression ${ }^{8}$, and produce interleukin (IL)-21 and IL-4 that together optimally drive B-cell affinity maturation and antibody specificity ${ }^{9,10}$. ICOS expression on $\mathrm{T}_{\mathrm{FH}}$ is crucial for both $\mathrm{T}_{\mathrm{FH}}$ differentiation and immune function ${ }^{8}$. An expansion of $\mathrm{T}_{\mathrm{FH}}$ cells has been observed in HIV infection ${ }^{11}$ and simian immunodeficiency virus (SIV) infection $^{12}$, yet this expansion does not correlate with improved $\mathrm{GC}$ responses. Rather, it has been shown that $\mathrm{T}_{\mathrm{FH}}$ exhibit impaired activity, partly due to $\mathrm{PD}-1$ ligation, manifested by reduced ICOS expression and inadequate production of IL-21 during HIV infection $^{13}$. It remains unclear whether additional factors may drive the dysregulation of $\mathrm{T}_{\mathrm{FH}}$ during HIV and SIV infection.

It has recently come to light that B-cell follicles contain a novel subset of regulatory $\mathrm{T}$ cell (Treg), termed follicular regulatory $\mathrm{T}$ cells $\left(\mathrm{T}_{\mathrm{FR}}\right)^{14-16} . \mathrm{T}_{\mathrm{FR}}$ display a unique transcriptional pattern overlapping that of both $\mathrm{T}_{\mathrm{FH}}$ and Treg, notably with combined expression of Bcl-6, Foxp3 and Blimp-1. $\mathrm{T}_{\mathrm{FR}}$ originate from Treg precursors, express CXCR5 and regulate GC responses through interactions with $\mathrm{T}_{\mathrm{FH}}{ }^{14-16}$. These studies were performed in mouse models, however, and the presence or function of $\mathrm{T}_{\mathrm{FR}}$ have not yet been described in HIV or SIV infection. Some ${ }^{17-21}$, but not all ${ }^{22-25}$ studies suggest proportional, not numerical, Treg increases in the peripheral blood of HIV-infected individuals. Studies in lymph nodes (LNs) and the spleen consistently suggest proportional increases of Treg in the context of HIV or SIV infection ${ }^{26-28}$, although absolute numbers have not been determined. The impact of Treg on HIV infection is controversial with some studies suggesting that Treg exert a beneficial effect by limiting autoimmunity, HIV replication and $\mathrm{CD}^{+}$T-cell depletion $17,18,24,25$, whereas others suggest that Treg have a detrimental effect by inhibiting HIV-specific immune responses and causing disease progression ${ }^{20,21,28,29}$. Although it is reported that Treg from HIV-infected individuals have lower suppressive capacity than those from uninfected individuals ${ }^{30}$, it has also been reported that HIV binding to Tregs enhances their suppressive activity and lymphoid homing ${ }^{31}$. Thus, understanding the role of Treg in HIV infection is still evolving ${ }^{32}$, and virtually nothing is known about $\mathrm{T}_{\mathrm{FR}}$ number and function in HIV infection. Here, we provide evidence for $\mathrm{HIV}$-mediated $\mathrm{T}_{\mathrm{FR}}$ expansion and the role of $\mathrm{T}_{\mathrm{FR}}$ in $\mathrm{T}_{\mathrm{FH}}$ dysregulation during HIV and SIV infection.

Through analyses of secondary lymphoid tissues from chronically HIV-infected humans and chronically SIV-infected rhesus macaques, as well as HIV infection ex vivo of human tonsils, we find that $\mathrm{T}_{\mathrm{FR}}$ are expanded both proportionally and numerically during infection. This expansion is due to a combination of factors, including viral entry and replication, Treg acquisition of CXCR5, transforming growth factor (TGF)- $\beta$ signalling, $\mathrm{T}_{\mathrm{FR}}$ proliferation, low apoptosis rates and increased regulatory dendritic cell (DC) activity. In addition, we demonstrate that $\mathrm{T}_{\mathrm{FR}}$ suppress $\mathrm{T}_{\mathrm{FH}}$ activity during infection by inhibiting $\mathrm{T}_{\mathrm{FH}}$ proliferation, IL-21 and IL-4 production and downregulating $\mathrm{T}_{\mathrm{FH}}$ ICOS expression. The identification of this potent regulator of GC dynamics provides a new therapeutic target for enhancement of anti-viral humoral immunity and vaccine efficacy to promote clearance of HIV.

\section{Results}

$\mathrm{T}_{\mathrm{FR}}$ are increased in chronic HIV and SIV Infections. To determine if $\mathrm{T}_{\mathrm{FR}}$ were present in human lymphoid tissues, we immunofluorescently labelled LN tissue cross-sections from HIV uninfected and HIV-infected individuals with antibodies to CD4, Foxp3, CD20 and IgD. CD $4{ }^{+}$Foxp $3^{+}$cells were readily detected throughout the LNs including follicular and GC regions, as shown in representative images (Fig. 1a and Supplementary Fig. 1a). Next, we quantified the number of $\mathrm{CD} 4{ }^{+}$Foxp $3^{+}$cells in total $\mathrm{LN}$, follicular $\left(\mathrm{CD} 20^{+}\right)$and $\mathrm{GC}\left(\mathrm{CD} 20^{+} \mathrm{IgD}^{-}\right)$regions using two to three tissue cross-sections per subject. In total $\mathrm{LN}$, the frequencies of $\mathrm{CD}_{4}^{+}{ }^{+}$Foxp $3^{+}$cells per $\mathrm{mm}^{2}$ were significantly higher in $\mathrm{HIV}$-infected individuals compared with uninfected controls, but frequencies of $\mathrm{CD} 4^{+} \mathrm{Foxp}^{+}$in follicular and GC regions did not differ significantly (Fig. 1b). LN enlargement is a hallmark of HIV infection, and therefore frequencies of $\mathrm{CD}^{+}{ }^{+}$Foxp $^{+}$cells per $\mathrm{mm}^{2}$ underestimate the true differences in absolute numbers of $\mathrm{CD} 4{ }^{+} \mathrm{Foxp}^{+}$cells. The average LN, follicular and GC areas in LN cross-sections, as determined by quantitative image analysis, were significantly larger in HIV-infected individuals than seronegative individuals (Fig. 1c). We then calculated the number of $\mathrm{CD} 4{ }^{+}$Foxp $3^{+}$cells per average LN tissue cross-section as well as within each compartment. Absolute numbers of $\mathrm{CD} 4{ }^{+}$Foxp $3^{+}$cells per average cross-section were significantly increased in HIV-infected individuals compared with HIV-uninfected individuals in all regions (Fig. 1d). The percentage of tissue area that stained positively for CD4 did not differ between HIV seropositive and seronegative individuals, indicating that these individuals had not yet experienced profound CD4 depletion in the LN (Supplementary Fig. 1b). In HIV-infected subjects, the percentage of activated (HLA-DR ${ }^{+} \mathrm{CD}_{3}{ }^{+}$) $\mathrm{LN} \mathrm{CD}^{+}{ }^{+} \mathrm{T}$ cells, as previously determined by flow cytometry ${ }^{33}$, did not correlate with number of Treg or $\mathrm{T}_{\mathrm{FR}}$ and was inversely correlated with $\mathrm{GC} \mathrm{T}_{\mathrm{FR}}$ in the average tissue cross-section (Supplementary Fig. 1c).

To determine if $\mathrm{T}_{\mathrm{FR}}$ are likewise increased during SIV infection, we analysed lymphoid cells from uninfected or SIVmac239-infected rhesus macaques by flow cytometry. As SIV infection reduces cell surface $\mathrm{CD} 4$, we gated on viable $\mathrm{CD} 3{ }^{+} \mathrm{CD}^{-}$cells, as previously described in humans ${ }^{33}$. The surface phenotype of $\mathrm{CD} 25^{\mathrm{hi}} \mathrm{CD} 127^{-}$has been shown in humans to encompass Tregs and allow for live cell sorting ${ }^{34-36}$. We validated that this phenotype accurately detects Tregs in SIV-uninfected and SIV-infected rhesus macaques (Fig. 2a). Here, Tregs were defined as viable $\mathrm{CD} 3{ }^{+} \mathrm{CD} 8-\mathrm{CD} 25^{\mathrm{hi}} \mathrm{CD} 127^{-}$, whereas $\mathrm{T}_{\mathrm{FR}}$ were defined as the subpopulation that are $\mathrm{CXCR}^{+}$, and GC $\mathrm{T}_{\mathrm{FR}}$ as the subpopulation that are CXCR5 $5^{\text {hi }}$ and PD- $1^{\text {hi }}$. In chronic SIV infection, percentages of Tregs, and particularly $\mathrm{T}_{\mathrm{FR}}$ and $\mathrm{GC} \mathrm{T}_{\mathrm{FR}}$, were significantly increased compared with SIV-uninfected animals (Fig. 2b). We next determined the ratio of regulatory cell populations to their nonregulatory counterpart and found the ratios of $\mathrm{T}_{\mathrm{FR}}$ to $\mathrm{T}_{\mathrm{FH}}$ and GC $\mathrm{T}_{\mathrm{FR}}$ to $\mathrm{GC} \mathrm{T}_{\mathrm{FH}}$ were significantly higher than those from SIVuninfected animals, whereas the overall ratio of Treg/non-Treg $\mathrm{CD}^{+}{ }^{+} \mathrm{CD} 8{ }^{-}$cells did not differ between infected and uninfected animals (Fig. 2c). Treg, $\mathrm{T}_{\mathrm{FR}}$ and $\mathrm{GC} \mathrm{T}_{\mathrm{FR}}$ subsets also expressed significantly higher levels of CTLA-4 in SIV-infected compared with SIV-uninfected animals (Fig. 2d).

$\mathrm{T}_{\mathrm{FR}}$ expansion is mediated by $\mathrm{HIV}$ infection. To characterize mechanisms underlying $\mathrm{T}_{\mathrm{FR}}$ expansion in HIV/SIV infection, we utilized an ex vivo model of HIV-1 infection in human tonsil cells. Disaggregated tonsil cells were spinoculated with NL4-3 based X4- or R5-tropic green fluorescent protein (GFP) reporter viruses and cultured for 2 days. Productive infection was confirmed by the presence of GFP expression after 2 days and percentages of $\mathrm{GFP}^{+} \mathrm{T}_{\mathrm{FR}}$ ranged from 1 to $15 \%$. Using the flow gating strategy described above for rhesus macaques, we demonstrated that 
CD25 hi CD $127^{-}$cells encompassed the majority of Foxp3 ${ }^{+}$cells (Fig. 3a). Compared with mock-spinoculated tonsil cells, a 24-h stimulation of mock-spinoculated tonsil cells with phorbol 12myristate 13-acetate (PMA) and ionomycin did not significantly increase $\mathrm{T}_{\mathrm{FR}}$, whereas the positive control of exogenous TGF- $\beta$ (ref. 37) did (Fig. 3b). A more marked expansion of $\mathrm{T}_{\mathrm{FR}}$ was observed with either X4- or R5-spinoculation (Fig. 3b). Pretreatment of cells before spinoculation with chemokine co-receptor antagonists, bicyclam (AMD) for X4 and maraviroc (MVC) for R5, inhibited on average 80 and $86 \%$ of productive $\mathrm{HIV}$ infection, respectively. Both AMD and MVC prevented $\mathrm{T}_{\mathrm{FR}}$ expansion (Fig. 3b). To determine if $\mathrm{T}_{\mathrm{FR}}$ expansion represented true numerical increases, mock- and $\mathrm{X} 4$-spinoculated cultures were analysed using flow cytometry counting beads. Total $\mathrm{CD}^{+}{ }^{+} \mathrm{CD} 8{ }^{-}$cells were decreased and $\mathrm{T}_{\mathrm{FH}}$ cells were slightly lower 2 days after X4-spinoculation compared with
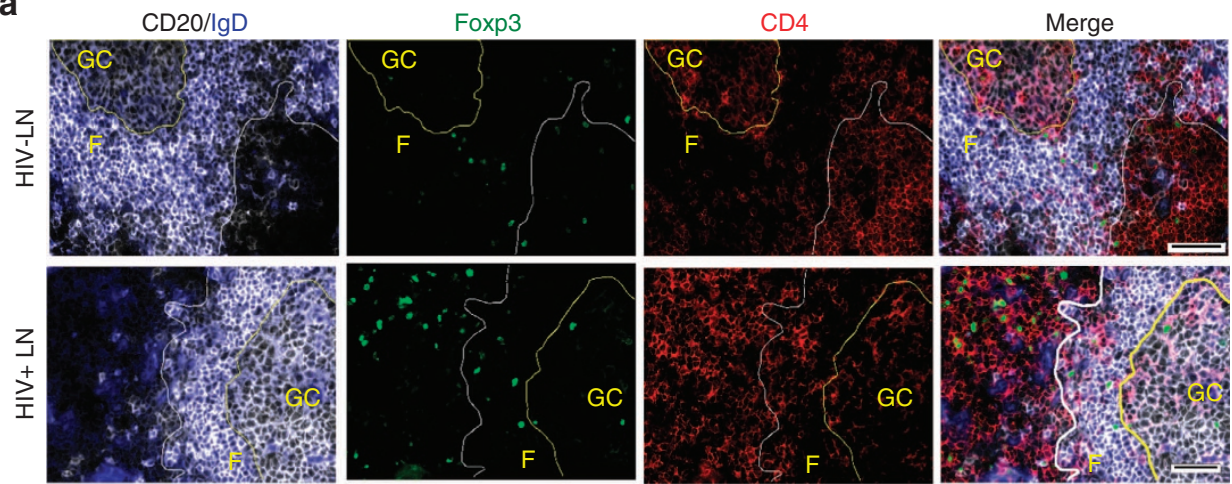

b
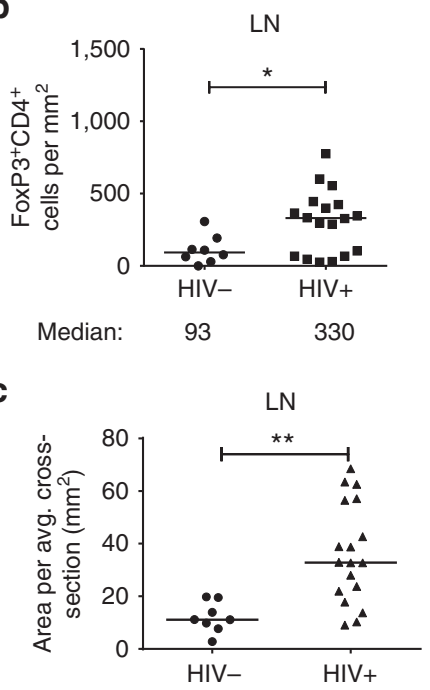

Median: $\quad 11$

33

d

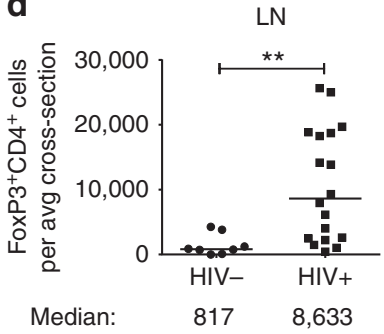

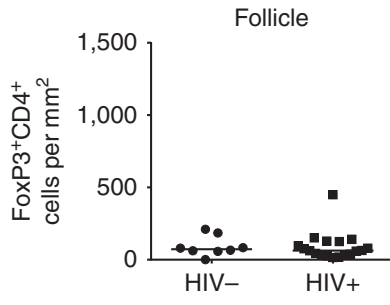

63

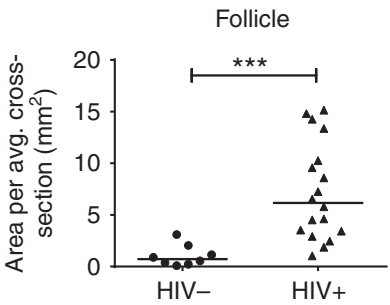

0.7
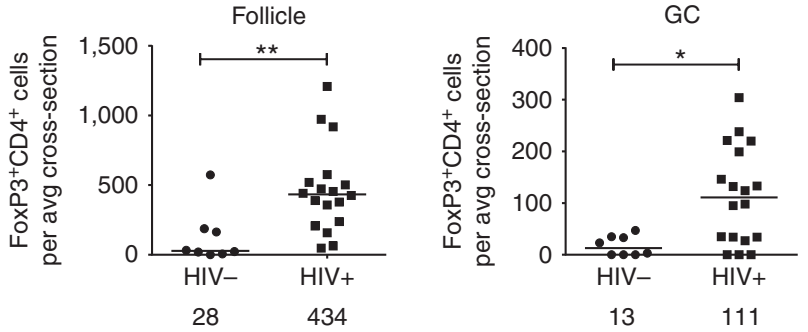

Figure 1 | $\mathbf{T}_{\mathbf{F R}}$ expansion in human lymph nodes (LNs) during HIV infection. (a) Representative images of immunofluorescently stained LN sections from a subject with chronic, untreated HIV infection $(n=17)$ and an uninfected control subject $(n=8)$. LNs were stained with fluorescently labelled antibodies to CD20 (white), IgD (blue), Foxp3 (green) and CD4 (red). Follicle (F) was defined as CD20 ${ }^{+}$(white line) and germinal centre (GC) was defined as $\mathrm{CD} \mathrm{O}^{+} \mathrm{IgD}{ }^{-}$(yellow line). Images were scanned at $\times 60$ magnification and scale bars equal $20 \mu \mathrm{m}$. (b) Foxp3 ${ }^{+} \mathrm{CD}^{+}{ }^{+}$cells were quantified in different regions of immunofluorescently stained LN shown in a from uninfected $(n=8)$ and HIV-infected $(n=17)$ subjects using visual inspection and quantitative image analysis to determine areas. (c) The average areas of total (LN), follicular and GC regions per LN cross-section were determined by quantitative image analysis. (d) The average number of $\mathrm{CD} 4{ }^{+}$Foxp3 ${ }^{+}$cells per $\mathrm{LN}, \mathrm{F}$ and $\mathrm{GC}$ cross-section was calculated by multiplying the frequency of $\mathrm{CD}^{+}{ }^{+}$Foxp3 $^{+}$cells per $\mathrm{mm}^{2}$ (b) by the average area of each region (c) for each subject. The horizontal bars of each graph indicate the median value and are listed where appropriate for clarity. Statistical analyses were performed by Mann-Whitney (Wilcoxon) tests to compare unpaired, nonparametric values and significance is denoted by asterisks where ${ }^{\star} P<0.05$ and ${ }^{* \star} P<0.01$. 
a

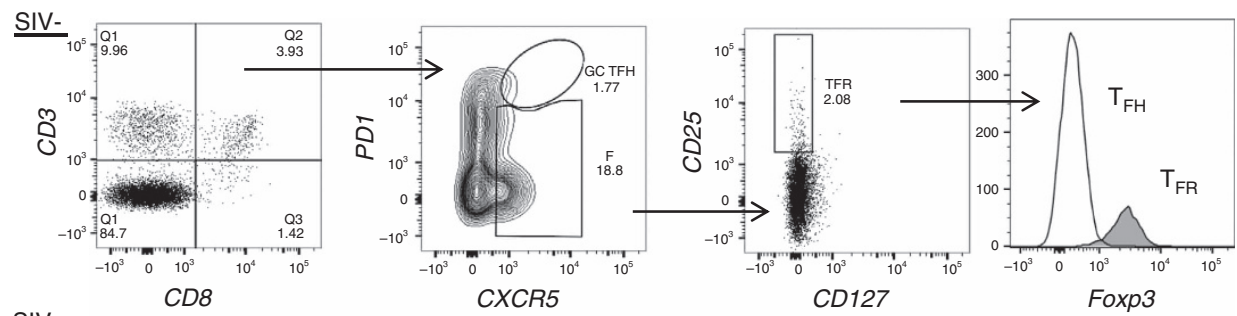

$\underline{\mathrm{SIV}}+$

$\begin{array}{lll}\text { CXCR5 } & \text { CD127 } & \text { Foxp3 }\end{array}$
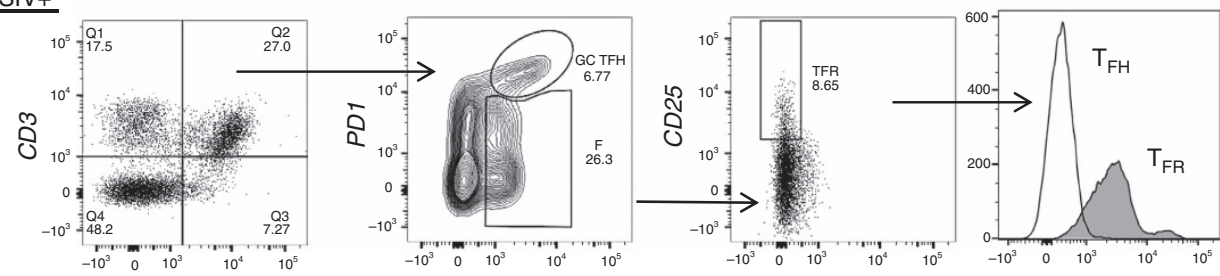

CD8

CXCR5

CD127

Foxp3
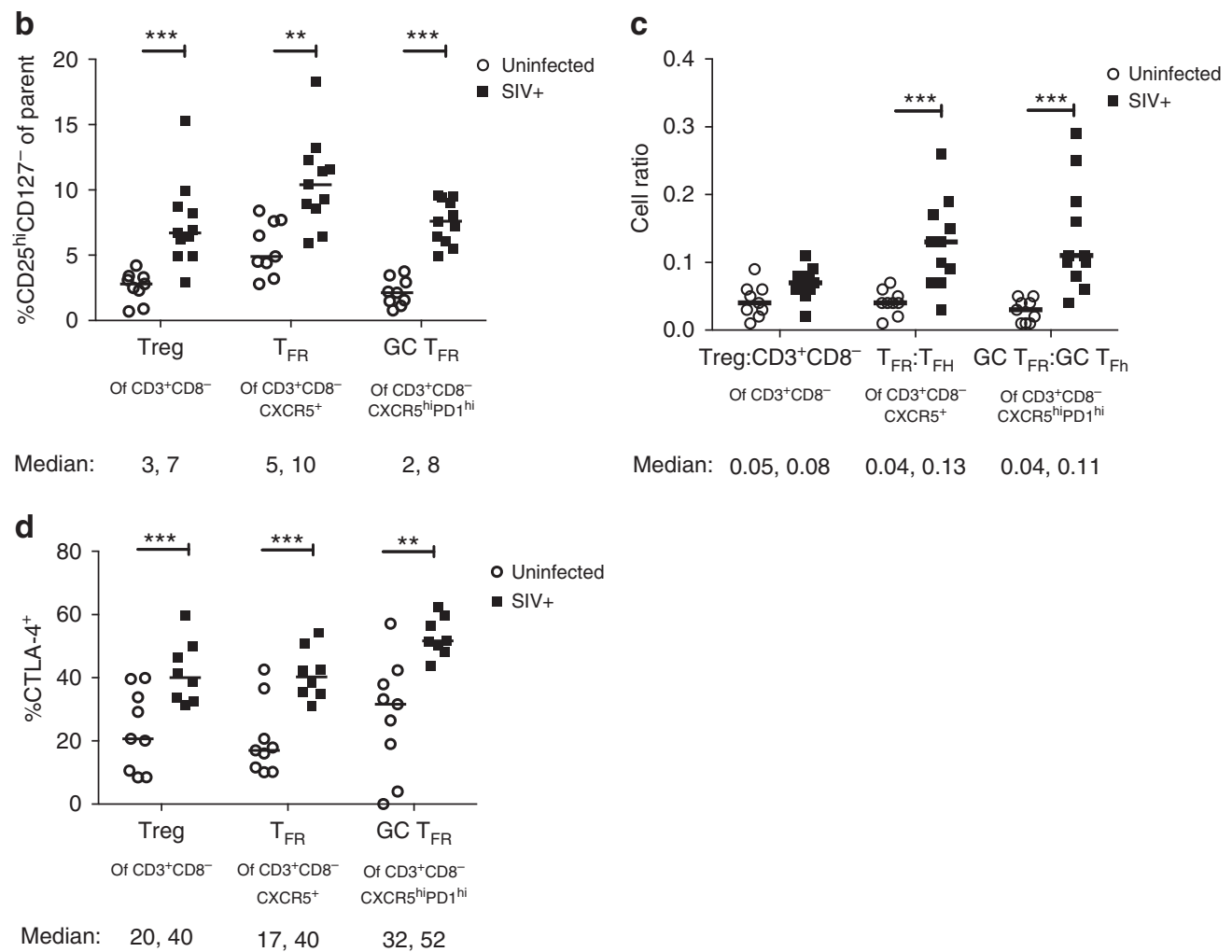

Figure 2 | $\mathbf{T}_{\mathbf{F R}}$ expansion in lymphoid tissues during chronic SIV infection. (a) Disaggregated lymph node and spleen cells from SIV uninfected ( $n=9$ ) or chronically SIV-infected rhesus macaques $(n=11)$ were analysed by flow cytometry. Representative examples of flow cytometry gating are shown. Of viable $\mathrm{CD} 3^{+} \mathrm{CD} 8^{-}$cells, follicular subsets were defined as CXCR5 ${ }^{+}$cells (F) and germinal centre subsets were defined as CXCR5 ${ }^{\text {hipD- }} \mathrm{1}^{\text {hi }}$ cells (GC). Of these subsets, regulatory cells were defined as CD25 hi CD127 ${ }^{-}$. $\mathrm{T}_{\mathrm{FR}}\left(\mathrm{CXCR} 5^{+} \mathrm{CD} 25^{\mathrm{hi}} \mathrm{CD} 127^{-}\right)$were Foxp $3^{+}$, whereas $\mathrm{T}_{\mathrm{FH}}\left(\mathrm{CXCR} 5^{+} \mathrm{CD} 25^{\mathrm{lo} /-}\right)$ were Foxp3- $^{-}$. (b) The percentages of each rhesus macaque regulatory subset, as analysed in a are shown. (c) The ratios of each regulatory cell population to its non-regulatory cell counterpart are shown. (d) The percentage of total CTLA-4 expression is shown in SIV-uninfected $(n=9)$ and chronically SIV-infected $(n=8)$ rhesus macaques. The horizontal bars of each graph indicate the median value and are listed where appropriate for clarity. Statistical analyses were performed by Mann-Whitney (Wilcoxon) tests to compare unpaired, nonparametric values and significance is denoted by asterisks where ${ }^{\star} P<0.05$,

${ }^{\star \star} P<0.01$ and ${ }^{\star \star \star} P<0.001$.

mock-spinoculated cells (Fig. $3 \mathrm{c}$ ). Conversely, the $\mathrm{T}_{\mathrm{FR}}$ population was approximately threefold higher in X4-spinoculated cells compared with mock-spinoculated cells (Fig. 3c). We further confirmed the phenotype of $\mathrm{T}_{\mathrm{FR}}$ by determining expression of the transcription factors Bcl-6 and Blimp-1, and evaluated the effects of ex vivo HIV-1 infection on their expression. Bcl-6 expression was significantly higher in both $\mathrm{T}_{\mathrm{FH}}$ and $\mathrm{T}_{\mathrm{FR}}$ compared with non-follicular (CXCR5 ${ }^{-}$) populations in mock-spinoculated cells at day 2 (Fig. 3d). With $\mathrm{X} 4$ or $\mathrm{R} 5$ spinoculation, $\mathrm{T}_{\mathrm{FH}}$ had significantly lower Bcl-6 expression compared with mockspinoculated cells, whereas Bcl-6 expression in $T_{F R}$ was not significantly altered by HIV spinoculation (Fig. 3d). Blimp-1 expression was significantly higher in non-follicular and $\mathrm{T}_{\mathrm{FR}}$ populations compared with $\mathrm{T}_{\mathrm{FH}}$ in mock-spinoculated cells at day 2, but was not significantly altered after X4 or R5 spinoculation (Fig. 3e). 

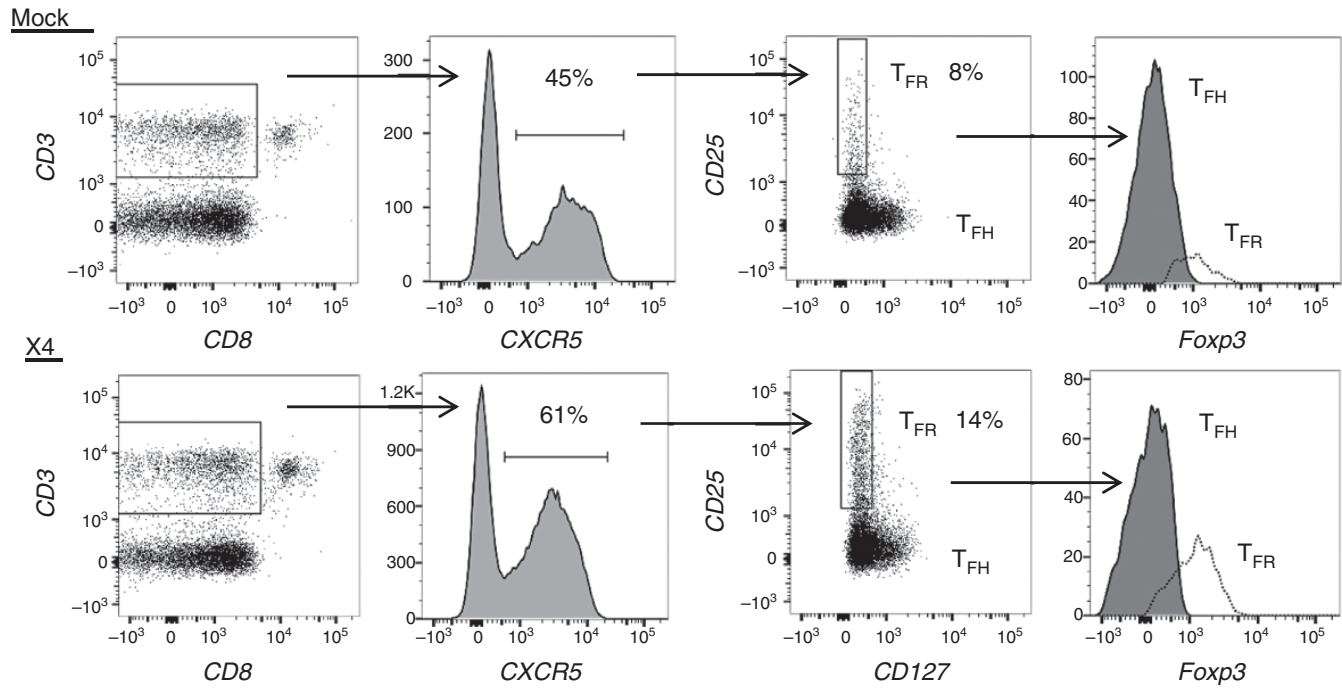

b

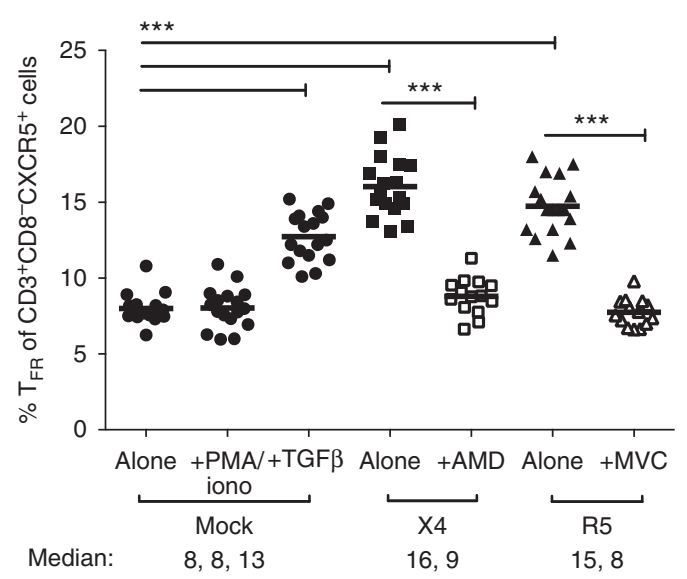

C
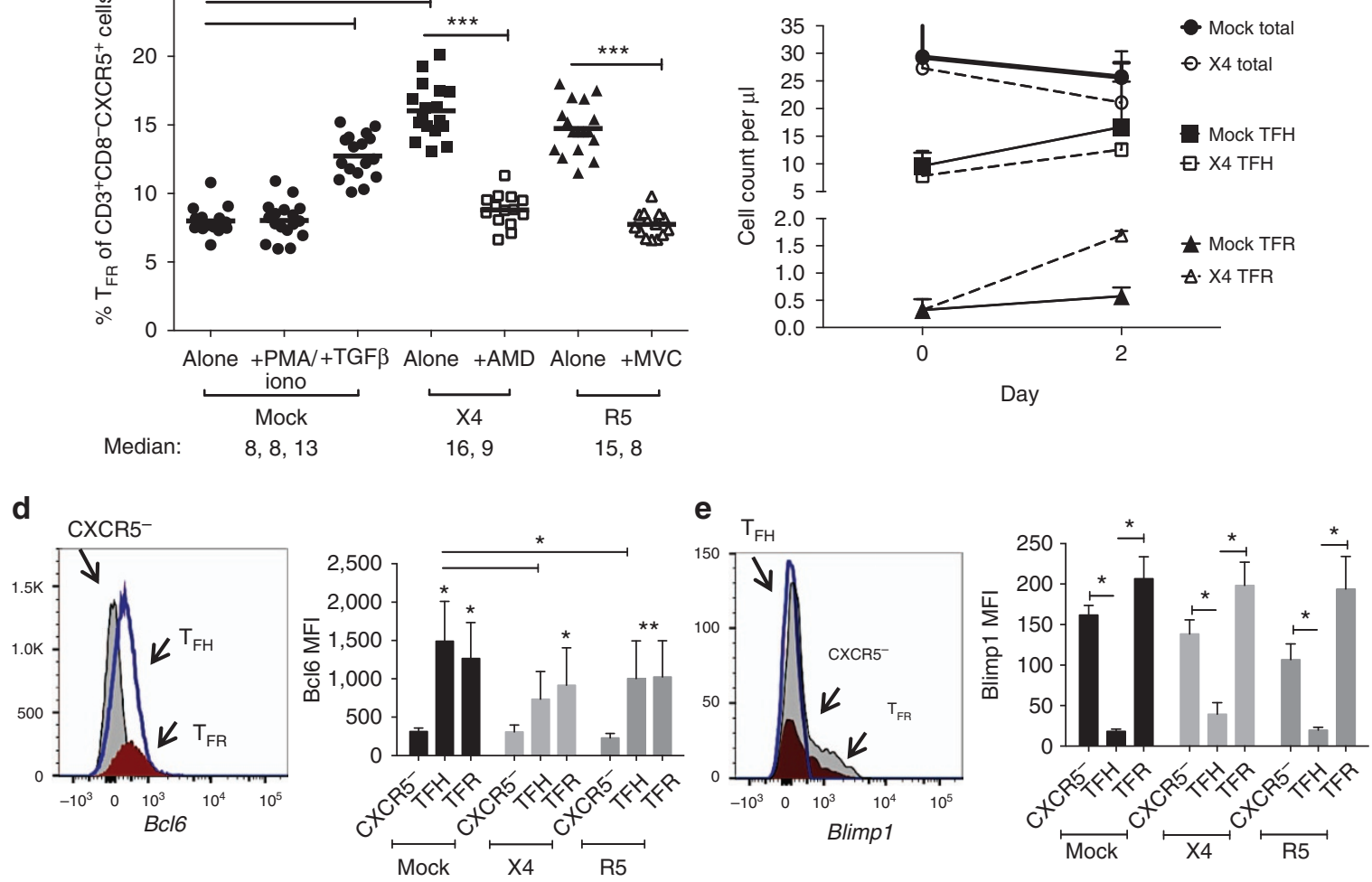

Figure 3 | HIV entry and replication promote $\mathbf{T}_{\mathbf{F R}}$ expansion. Disaggregated tonsil cells were spinoculated with X4 or R5 HIV and $T_{F R}$ populations were analysed by flow cytometry $(n=15)$. (a) A representative example of tonsil cell flow gating. From viable $C D 3^{+} \mathrm{CD}^{-}$cells, $\mathrm{T}_{\mathrm{FR}}$ are defined as $\mathrm{CXCR5}^{+}$and $\mathrm{CD} 25^{\mathrm{hi}} \mathrm{CD} 127^{-}$. $\mathrm{T}_{\mathrm{FR}}$ cells contain Foxp3 ${ }^{+}$cells, whereas remaining $\mathrm{T}_{\mathrm{FH}}\left(\mathrm{CXCR} 5^{+} \mathrm{CD} 5^{\mathrm{lo} /{ }^{-}}\right.$) cells are Foxp3 ${ }^{-}$. (b) Percentages of $\mathrm{T}_{\mathrm{FR}}$ determined by gating strategies in a are shown. Experimental conditions include mock-spinoculated cells cultured with $\mathrm{PMA}\left(50 \mathrm{ng} \mathrm{ml}^{-1}\right.$ ) and ionomycin $\left(1 \mu \mathrm{g} \mathrm{ml}^{-1}\right)$ or exogenous TGF- $\beta\left(100 \mathrm{ng} \mathrm{ml}^{-1}\right)$ for $24 \mathrm{~h}$ and cells pretreated to block CXCR4 (AMD, $\left.200 \mu \mathrm{M}\right)$ and CCR5 (MVC, $\left.2 \mu \mathrm{M}\right)$. (c) Using flow cytometry counting beads, the number of cells per $\mu$ were determined for total $\left(\mathrm{CD} 3^{+} \mathrm{CD} 8^{-}\right), \mathrm{T}_{\mathrm{FH}}\left(\mathrm{CXCR} 5^{+} \mathrm{CD} 25^{\mathrm{lo} /-}\right)$ and $\mathrm{T}_{\mathrm{FR}}$ $\left(\mathrm{CXCR5}{ }^{+} \mathrm{CD}_{25} 5^{\mathrm{hi}} \mathrm{CD} 127^{-}\right.$) subsets in mock- and X4-spinoculated samples $(n=3)$. (d) Bcl-6 expression is shown in CXCR5 - (grey), $\mathrm{T}_{\mathrm{FH}}$ (blue) and $\mathrm{T}_{\mathrm{FR}}$ (red) populations after mock-, $\mathrm{X} 4$ - or R5-spinoculation $(n=5)$. (e) Blimp-1 expression was also determined as in $\mathbf{d}$. The horizontal bars of each graph indicate the median value and are listed where appropriate for clarity. Statistical analyses were performed by Friedman nonparametric tests (b,d,e) and significance is denoted by asterisks where ${ }^{\star} P<0.05,{ }^{* \star} P<0.01$ and ${ }^{* \star *} P<0.001$.

IDO and TGF- $\beta$ production contribute to $T_{F R}$ expansion. To further address viral life cycle contribution to $\mathrm{T}_{\mathrm{FR}}$ expansion, tonsil cells were treated with the integrase inhibitor raltegravir (RAL) after spinoculation. RAL blocked on average $91 \%$ of productive HIV infection and significantly decreased, but did not fully suppress, $\mathrm{T}_{\mathrm{FR}}$ expansion (Fig. $4 \mathrm{a}$ ). In addition, TGF- $\beta$ is crucial for stable Foxp3 expression in Tregs, so culture supernatants were analysed for TGF- $\beta$ production. Stimulation of mock-spinoculated cells with PMA and ionomycin did not lead to increased TGF- $\beta$ production, whereas the presence of either X4 

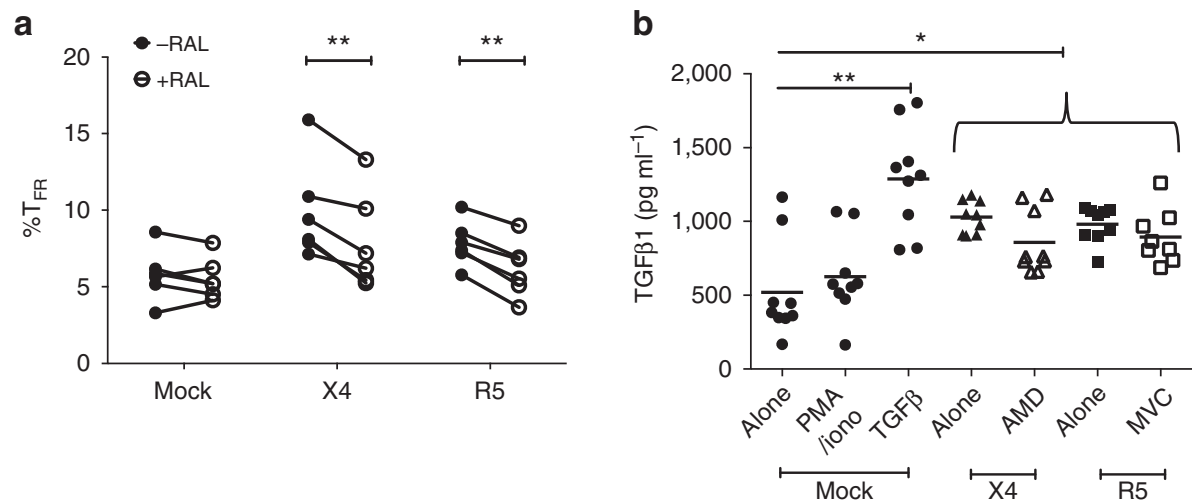

Median: $540603 \quad 1,2921,027900974889$
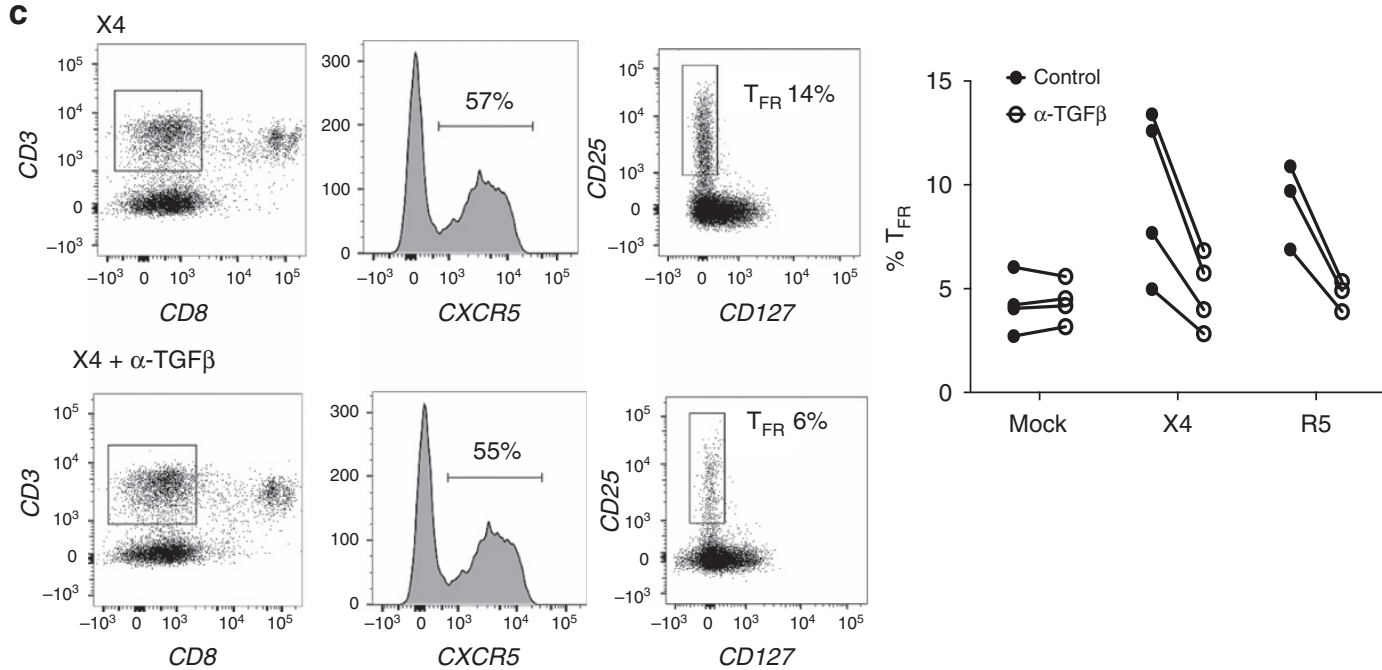

d
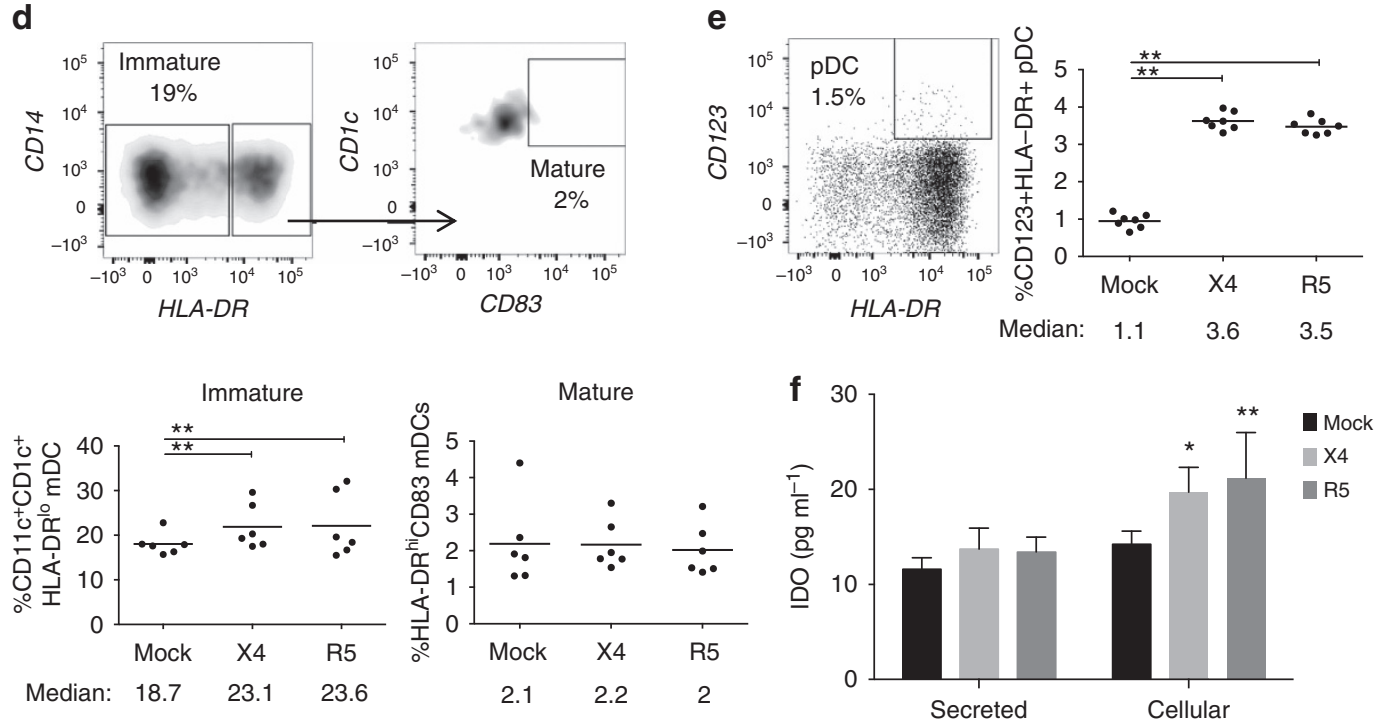

Figure 4 | Viral replication, TGF- $\boldsymbol{\beta}$ signalling and regulatory dendritic cells promote $\mathbf{T}_{\mathbf{F R}}$ expansion. Tonsil cells were mock-spinoculated or spinoculated with X4 or R5 virus and cultured for 2 days under a variety of conditions. (a) Tonsil cells were treated with the integrase inhibitor raltegravir (RAL, $10 \mu \mathrm{M}$ ) during culture to allow viral entry but prevent integration and percentages of $T_{F R}$ determined $(n=5)$. (b) Tonsil cells were cultured under the conditions shown and TGF- $\beta-1$ levels were measured in culture supernatant by ELISA $(n=8)$. (c) Tonsil cells were cultured in the presence of TGF- $\beta$ blocking antibodies $\left(2 \mu \mathrm{g} \mathrm{ml}^{-1}\right)$ and the percentages of $\mathrm{T}_{\mathrm{FR}}$ were measured $(n=4)$. Addition of anti-TGF- $\beta$ antibodies did not influence cell viability. (d) Tonsil cells were cultured under the conditions shown and then analysed for the presence of immature myeloid DCs (CD11c ${ }^{+} \mathrm{CD} 1 \mathrm{c}^{+} \mathrm{HLA}-\mathrm{DR}$ R) and mature myeloid $\mathrm{DCs}\left(\mathrm{CD} 11 \mathrm{c}^{+} \mathrm{CD} 1 \mathrm{c}^{+} \mathrm{HLA}-\mathrm{DR}{ }^{+} \mathrm{CD}_{3}{ }^{+} ; n=6\right)$. (e) Samples in $\mathbf{d}$ were also analysed for activated plasmacytoid $\mathrm{DCs}\left(\mathrm{CD} 123^{+} \mathrm{HLA}-\mathrm{DR}{ }^{+}, n=6\right)$.

(f) Cell culture supernatants and lysates from $\mathbf{d}$,e were analysed by ELISA to quantitate IDO production $(n=6)$. The horizontal bars of each graph indicate the median value and are listed where appropriate for clarity. Statistical analyses were performed using Wilcoxon matched-pairs tests (a,c) or MannWhitney ranked sums tests $(\mathbf{b}, \mathbf{d}-\mathbf{f})$ and significance is denoted by asterisks where ${ }^{\star} P<0.05,{ }^{\star \star} P<0.01$ and ${ }^{\star \star \star} P<0.001$. 
or R5 virus, even with AMD or MVC pretreatments before spinoculation, led to significant increases in TGF- $\beta$ (Fig. 4b). When tonsil cells were cultured in the presence of TGF- $\beta$ neutralizing antibodies, $\mathrm{T}_{\mathrm{FR}}$ expansion was inhibited in both X4- and R5-spinoculation (Fig. 4c).

Regulatory DC are described as myeloid and plasmacytoid DCs that have an immature or semi-mature phenotype and produce anti-inflammatory molecules such as indoleamine 2,3-dioxygenase (IDO) that generates Tregs ${ }^{38}$. It has previously been reported that regulatory DCs inhibit effector T-cell function by exhibiting a lack of co-stimulatory molecule expression ${ }^{39}$ and can produce IDO in lymphoid tissues during HIV and SIV infection ${ }^{40-42}$. In tonsil cultures, there were significantly more immature myeloid DCs with both X4- and R5-spinoculation, but no significant increase in mature myeloid DCs when compared with mock-spinoculated cells (Fig. 4d). X4- and R5-spinoculation also significantly increased activated plasmacytoid DC compared with mock spinoculation (Fig. 4e). Culture supernatants and lysed cells were then measured for IDO production. There was a significant increase in IDO with either X4- or R5-spinoculation compared with mock-spinoculation (Fig. 4f). We further analysed these culture supernatants for interferon (IFN)- $\gamma$ production, as IFN signalling is upstream of IDO production. $\mathrm{X} 4$ - and R5-spinoculated cultures tended to have higher levels of IFN- $\gamma$, but this increase was not statistically significant (Supplementary Fig. 2a).

$\mathrm{T}_{\mathrm{FR}}$ have high proliferation and low apoptosis rates. In mice, $\mathrm{T}_{\mathrm{FR}}$ arise from conventional Tregs, rather than from $\mathrm{T}_{\mathrm{FH}}{ }^{15}$. To investigate the origin of $\mathrm{T}_{\mathrm{FR}}$ in human cells, we evaluated whether tonsil $\mathrm{T}_{\mathrm{FH}}$ phenotypically converted to $\mathrm{T}_{\mathrm{FR}}$ or whether Tregs gain CXCR5 expression. $\mathrm{T}_{\mathrm{FH}}\left(\mathrm{CD} 3{ }^{+} \mathrm{CD} 8^{-} \mathrm{CXCR} 5^{+} \mathrm{CD} 25^{-}\right)$and non-follicular $\left(\mathrm{CD} 3{ }^{+} \mathrm{CD} 8^{-} \mathrm{CXCR}^{-}\right)$T-cell populations were sorted and cultured without HIV-spinoculation for 2 days. Interestingly, $\mathrm{T}_{\mathrm{FH}}$ did not acquire Foxp3 expression, even in the presence of exogenous TGF- $\beta$, whereas a small population of cells from the initial CXCR5 ${ }^{-}$population acquired CXCR5 expression (Fig. 5a). These cells, labelled 'new' $\mathrm{T}_{\mathrm{FR}}$, expressed high levels of Foxp3 (Fig. 5a).

We further hypothesized that cell proliferation may contribute to $\mathrm{T}_{\mathrm{FR}}$ expansion. We utilized 5-bromodeoxyuridine ( $\left.\mathrm{BrdU}\right)$ labelling in tonsil cells to measure the relative rates of $\mathrm{T}_{\mathrm{FR}}$ and $\mathrm{T}_{\mathrm{FH}}$ proliferation. Tonsil cells were mock-, $\mathrm{X} 4-$ or R5-spinoculated and BrdU DNA incorporation was measured after 2 days by flow cytometry. BrdU incorporation rates were low overall, but in the context of HIV infection, $\mathrm{T}_{\mathrm{FR}}$ incorporated significantly more BrdU than $\mathrm{T}_{\mathrm{FH}}$ (Fig. $5 b$ ).

To evaluate the duration of tonsil $\mathrm{T}_{\mathrm{FR}}$ increases, we extended the counting experiments in Fig. $3 \mathrm{c}$ for 5 days. Total $\mathrm{CD}^{+}$ $\mathrm{CD}^{-}, \mathrm{T}_{\mathrm{FH}}$ and $\mathrm{T}_{\mathrm{FR}}$ populations from mock-spinoculated samples remained numerically stable up to 5 days (Fig. $5 \mathrm{c}$ ). In X4-spinoculated samples, total and $\mathrm{T}_{\mathrm{FH}}$ cells declined by day 5, whereas $\mathrm{T}_{\mathrm{FR}}$ were elevated at day 2 and remained so through day 5 (Fig. $5 \mathrm{c}$ ). We also analysed cell death rates by Annexin-V and propidium iodide (PI) staining in mock- and $\mathrm{X} 4$-spinoculated tonsil cells. Total $\mathrm{CD} 3{ }^{+} \mathrm{CD}^{-}$cells and $\mathrm{T}_{\mathrm{FH}}$ cells displayed increased rates of late apoptosis $\left(\right.$ Annexin ${ }^{+} \mathrm{PI}^{+}$) and necrosis $\left(\mathrm{PI}^{+}\right)$in $\mathrm{X} 4$-spinoculated samples compared with mock-spinoculated cells (Fig. 5d). The majority of $\mathrm{T}_{\mathrm{FR}}$ remained in a state of viability or early apoptosis $\left(\right.$ Annexin $^{+}$) in $\mathrm{X} 4$-spinoculated tonsil cells, similar to what was seen with mock-spinoculated cells (Fig. 5d). To determine if this occurs during in vivo infection, we analysed Annexin- $\mathrm{V}$ staining in disaggregated rhesus macaque lymphoid cells. The levels of Annexin- $\mathrm{V}$ staining in total $\mathrm{CD} 3^{+} \mathrm{CD}^{-}$and Treg populations were significantly higher in SIV-infected animals compared with SIV-uninfected animals (Fig. 5e). There was not a significant difference in the level of Annexin- $V$ staining in $T_{F H}$ cells in SIV-infected compared with SIV-uninfected animals (Fig. 5e). In contrast, the levels of Annexin-V staining in $\mathrm{T}_{\mathrm{FR}}$ and $\mathrm{GC} \mathrm{T}_{\mathrm{FR}}$ were significantly lower in SIV-infected animals compared with SIV-uninfected animals (Fig. 5e).

$\mathrm{T}_{\mathrm{FR}}$ regulatory phenotypes in HIV infection ex vivo. We next sought to determine the regulatory phenotype of tonsil $\mathrm{T}_{\mathrm{FR}}$ during infection. CTLA-4 and LAG-3 are used to contact and inhibit effector cell function, GITR is expressed on activated and proliferating cells, whereas galectin receptors are an important family in promoting effector cell apoptosis ${ }^{43}$. Both X4- and R5-spinoculation caused $\mathrm{T}_{\mathrm{FR}}$ to significantly upregulate total CTLA-4 (Fig. 6a) and LAG-3 (Fig. 6b), as well as GITR and galectin-3, whereas galectin-9 expression was not altered (Supplementary Fig. 2b). Regulation of $\mathrm{T}_{\mathrm{FH}}$ has previously shown to occur through PD-1 ligation ${ }^{13}$, however, PD-L1 was expressed on fewer than $3 \%$ of $\mathrm{T}_{\mathrm{FR}}$ following either mock or $\mathrm{X} 4$ spinoculation $(n=3)$. Blockade of chemokine co-receptors partially inhibited CTLA-4 and GITR upregulation on $\mathrm{T}_{\mathrm{FR}}$ (Fig. 6a and Supplementary Fig. 2a). Blockade of CD4 before spinoculation inhibited upregulation of CTLA-4 (Supplementary Fig. 3a) and GITR (Supplementary Fig. 3b) during infection. Blockade of TGF- $\beta$ led to downregulation of CTLA-4 on $\mathrm{T}_{\mathrm{FR}}$ during infection (Supplementary Fig. 3c).

IL-10 regulates effector cell function, whereas TGF- $\beta$ prevents inflammatory responses and promotes Foxp3 expression ${ }^{43}$. IL-10 and TGF- $\beta$ (LAP-1) production by tonsil $\mathrm{T}_{\mathrm{FR}}$ was determined by intracellular cytokine staining. Mock-spinoculated cultures treated with exogenous TGF- $\beta$ as a positive control showed a significant increase of $\mathrm{IL}-10^{+} \mathrm{T}_{\mathrm{FR}}$ (Fig. 6c). X4- and R5-spinoculation led to significant increases of $\mathrm{IL}^{-10^{+}} \mathrm{T}_{\mathrm{FR}}$, which tended to be higher than TGF- $\beta$-treated $\mathrm{T}_{\mathrm{FR}}$ (Fig. 6c). Similar trends were observed in regards to TGF- $\beta^{+} \mathrm{T}_{\mathrm{FR}}$ (Fig. 6d). In addition, analysis of culture supernatant showed that infection significantly upregulated IL-10 compared with mockspinoculated controls (Supplementary Fig. 2c), whereas the presence of X4 or R5 virus did not significantly increase IL-35 production (Supplementary Fig. 2d).

$T_{F R}$ dysregulate $T_{F H}$ activity. $T_{F R}$ have been shown to modulate $\mathrm{T}_{\mathrm{FH}}$ function and thereby control GC reactions in mice ${ }^{14-16}$. Given that $\mathrm{T}_{\mathrm{FH}}$ exhibit impaired function in chronic HIV infection $^{13}$ we investigated whether $\mathrm{T}_{\mathrm{FH}}$ were impaired by $\mathrm{T}_{\mathrm{FR}}$ in the tonsil model. We first compared the expression of ICOS, a key molecule for $\mathrm{T}_{\mathrm{FH}}$ maintenance and function, in $\mathrm{X} 4$ - or R5-spinoculation to mock-spinoculation. With both X4- and R5-spinoculation, $\mathrm{T}_{\mathrm{FH}}$ demonstrated a significant reduction of ICOS expression (Fig. 7a). We evaluated the role of Tregs in $\mathrm{T}_{\mathrm{FH}}$ ICOS downregulation by depleting $\mathrm{CD} 25^{+}$regulatory cells, which effectively removes all Foxp $3^{+}$cells from tonsil cell culture, and analysing $\mathrm{T}_{\mathrm{FH}}$ after 2 days. ICOS expression on $\mathrm{T}_{\mathrm{FH}}$ was high in mock-spinoculated controls regardless of the presence or absence of Treg (Fig. 7b). With X4- or R5-spinoculation, however, ICOS expression was not downregulated when Tregs were absent (Fig. 7b). Although $\mathrm{CD} 25^{+}$cell depletion effectively removes overall regulatory populations, we could not rule out that $\mathrm{T}_{\mathrm{FR}}$ may have functions differing from those of Tregs. We therefore examined the regulatory effects of $\mathrm{T}_{\mathrm{FR}}$ specifically by isolating tonsil $\mathrm{T}_{\mathrm{FH}}$ and adding $\mathrm{T}_{\mathrm{FR}}$ back to $\mathrm{T}_{\mathrm{FH}}$ at increasing ratios. In X4- and R5-spinoculated cultures, we observed that $\mathrm{T}_{\mathrm{FH}}$ ICOS levels were decreased as the ratio of $\mathrm{T}_{\mathrm{FR}}$ increased (Fig. 7c). 
a

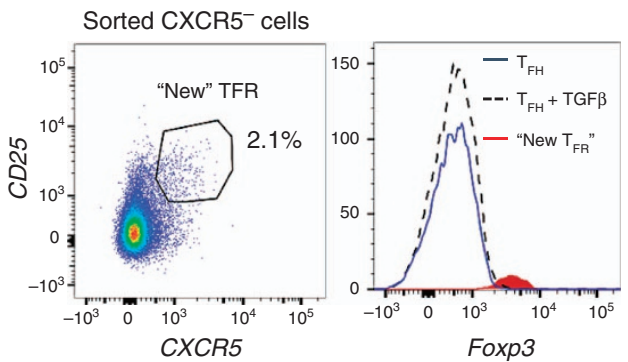

C

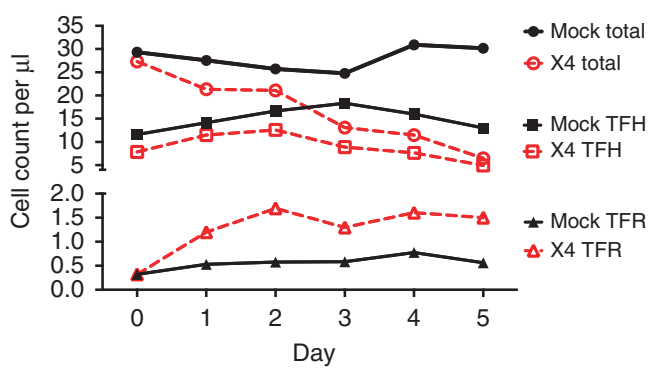

e

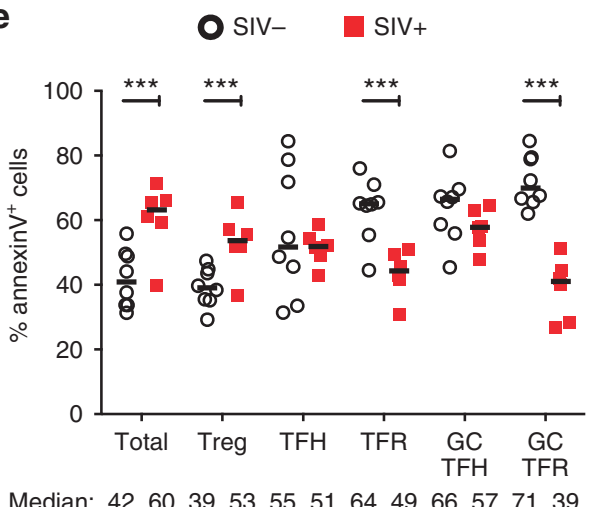

b
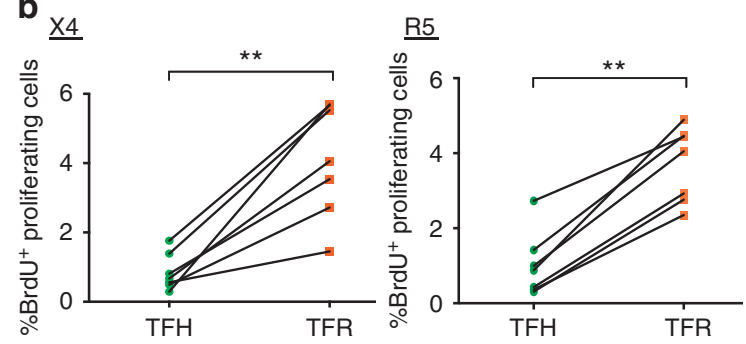

d

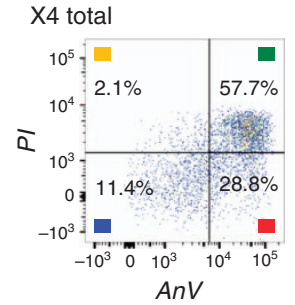

$\mathrm{X} 4 \mathrm{TFH}$

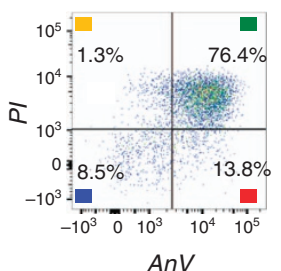

X4 TFR

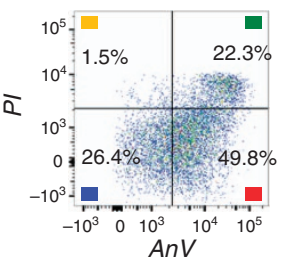

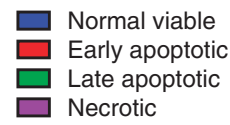
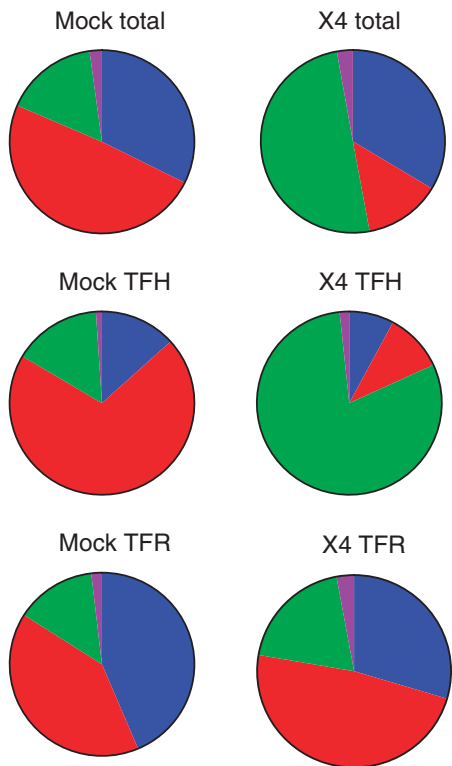

X4 TFR

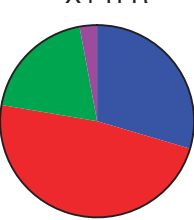

Figure 5 | Acquisition of CXCR5, enhanced proliferation and reduced apoptosis promote $\mathbf{T}_{\mathbf{F R}}$ expansion. (a) $\mathrm{T}_{\mathrm{FH}}$ and $\mathrm{CXCR5}{ }^{-} \mathrm{T}_{-}$-cell populations were sorted and cultured without stimulation, or $\mathrm{T}_{\mathrm{FH}}$ were cultured in the presence of exogenous TGF- $\beta$ (100 ng ml ${ }^{-1}$ ). CXCR5 expression was analysed on sorted CXCR5 ${ }^{-}$cells after 2 days and cells expressing CXCR5 are labelled as 'new $T_{F R}$ '. The Foxp3 expression levels of $T_{F H}, T_{F H}$ cultured with TGF- $\beta$ and 'new' $T_{F R}$ were determined $(n=3)$. (b) $T_{F H}$ and $T_{F R}$ were mock-, $X 4$ - or R5-spinoculated and cell proliferation measured by BrdU incorporation after 2 days of culture $(n=7)$. (c,d) A 5-day time course was performed to monitor T-cell population counts and rates of cell death with mock- or X4-spinoculated tonsil cells $(n=3)$. (c) Average counts of total $\left(\mathrm{CD} 3^{+} \mathrm{CD}^{-}\right.$, circles), $\mathrm{T}_{\mathrm{FH}}\left(\mathrm{CXCR} 5^{+} \mathrm{CD} 25^{\mathrm{lo} /-}\right.$, squares) and $\mathrm{T}_{\mathrm{FR}}\left(\mathrm{CXCR} 5^{+} \mathrm{CD} 25^{\mathrm{hi}} \mathrm{CD} 127^{-}\right.$, triangles) are shown for the duration of culture $(n=3)$. (d) Stages of cell death are shown at day 5 and defined as early apoptosis $\left(\right.$ Annexin $\left.V^{+}\right)$, late or advanced apoptosis (AnnexinV ${ }^{+} \mathrm{PI}^{+}$) and necrotic death $\left(\mathrm{PI}^{+} ; n=3\right)$. (e) Cell subsets from disaggregated lymphoid tissues of chronically SIV-infected $(n=6)$ and uninfected rhesus macaques $(n=8)$ were analysed for apoptosis by percent Annexin- $V$ binding. Cell phenotypes were defined as total $\left(\mathrm{CD} 3^{+} \mathrm{CD} 8^{-}\right)$, Treg $\left(\mathrm{CD} 3^{+} \mathrm{CD} 8-\mathrm{CD} 25^{\mathrm{hi}} \mathrm{CD} 127^{-}\right), \mathrm{T}_{\mathrm{FH}}\left(\mathrm{CD} 3^{+} \mathrm{CD} 8-\mathrm{CXCR} 5^{+} \mathrm{CD} 25^{\mathrm{lo} /-}\right), \mathrm{T}_{\mathrm{FR}}\left(\mathrm{CD} 3^{+} \mathrm{CD} 8-\mathrm{CXCR} 5^{+} \mathrm{CD}_{25} 5^{\mathrm{hi}} \mathrm{CD} 127^{-}\right), \mathrm{GC} \mathrm{T}_{\mathrm{FH}}$ $\left.\left(\mathrm{CD} 3^{+} \mathrm{CD} 8-\mathrm{CXCR} 5^{+} \mathrm{PD}\right)^{\mathrm{hi}} \mathrm{CD} 25^{\mathrm{lo} /-}\right)$ and $\mathrm{GC} \mathrm{T}_{\mathrm{FR}}\left(\mathrm{CD} 3^{+} \mathrm{CD} 8-\mathrm{CXCR} 5^{+} \mathrm{PD} 1^{\mathrm{hi}} \mathrm{CD} 25^{\mathrm{hi}} \mathrm{CD} 127^{-}\right)$. Statistical analyses were performed by Wilcoxon matched-pairs tests (b) or Mann-Whitney tests (e) and significance is denoted by asterisks where ${ }^{\star \star} P<0.01$ and ${ }^{* \star *} P<0.001$.

Previous studies using ex vivo suppression assays have shown that Treg inhibit $\mathrm{CD}^{+}{ }^{+} \mathrm{T}$-cell proliferation and cytokine production in HIV infection ${ }^{18,21}$. First, we investigated the ability of $\mathrm{T}_{\mathrm{FR}}$ to suppress proliferation of $\mathrm{T}_{\mathrm{FH}}$ in the context of ex vivo $\mathrm{HIV}$ infection. Tonsil $\mathrm{T}_{\mathrm{FH}}$ and $\mathrm{T}_{\mathrm{FR}}$ were isolated, spinoculated with either $\mathrm{X} 4$ or $\mathrm{R} 5$ virus, and cultured either alone or with equal numbers of $\mathrm{T}_{\mathrm{FR}}$ for 4 days in the presence of antiCD3/anti-CD28 antibodies and IL-2. $\mathrm{T}_{\mathrm{FR}}$ consistently inhibited proliferation of $\mathrm{T}_{\mathrm{FH}}$ in both $\mathrm{X} 4$ - and $\mathrm{R} 5$-spinoculated cultures (Fig. 7d).

Next, we investigated the role of $T_{F R}$ on $T_{F H}$ cytokine production. Initially, we observed that tonsil $\mathrm{T}_{\mathrm{FH}}$ display decreased IL-4 production in either X4- or R5-spinoculated cultures, whereas IL-21 production did not have a uniform trend (Supplementary Fig. 4a). Removal of $\mathrm{CD}_{2} 5^{+}$Tregs led to significant increases in IL-4 (Fig. 8a) and IL-21 (Fig. 8b) production by tonsil $\mathrm{T}_{\mathrm{FH}}$ following mock-, $\mathrm{X} 4$ - and R5-spinoculation and significant increases in IL-4 and IL-21 production by $\mathrm{T}_{\mathrm{FH}}$ in cells from both uninfected and chronically SIV-infected animals (Fig. 8c). We further validated these observations by co-culturing tonsil $\mathrm{T}_{\mathrm{FH}}$ with increasing ratios of $\mathrm{T}_{\mathrm{FR}}$ following spinoculation with $\mathrm{X} 4$ virus. The absence of $\mathrm{T}_{\mathrm{FR}}$ led to increased $\mathrm{T}_{\mathrm{FH}}$ production of IL-4 and IL-21 (Fig. 8d). The regulation of $\mathrm{T}_{\mathrm{FH}}$ was $\mathrm{T}_{\mathrm{FR}}$ dose-dependent, as an increasing ratio of $\mathrm{T}_{\mathrm{FR}}$ led to increasing inhibition of $\mathrm{T}_{\mathrm{FH}}$ IL-4 and IL-21 production (Fig. $8 \mathrm{~d}$ ). To determine if the suppressive 
a

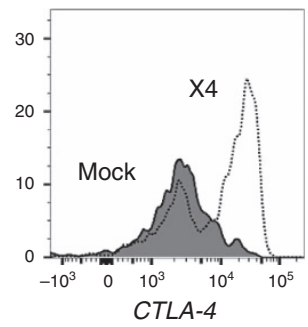

b

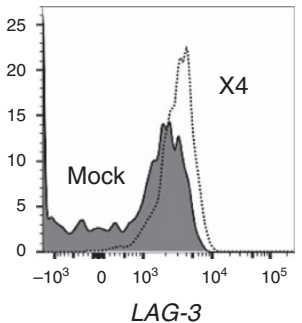

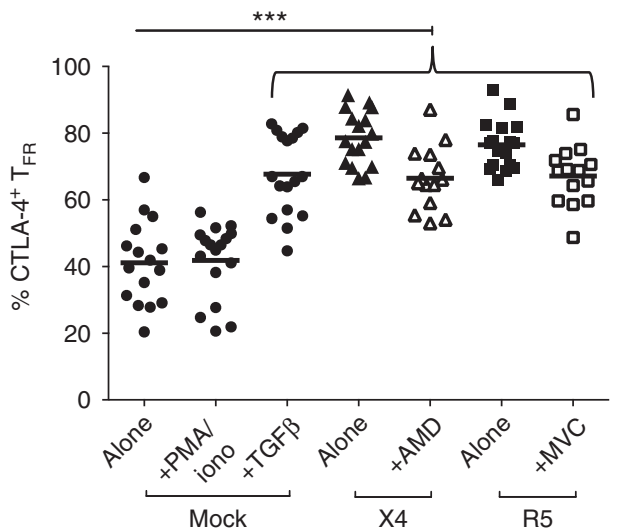

Median: $\quad 42,41,67 \quad 78,65 \quad 75,69$

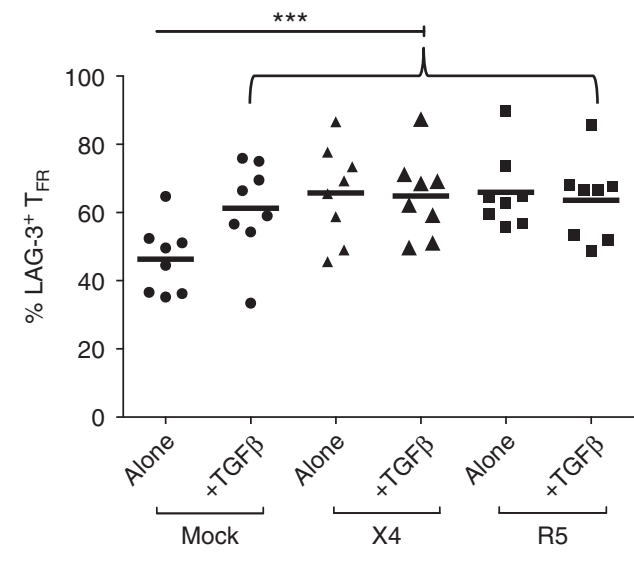

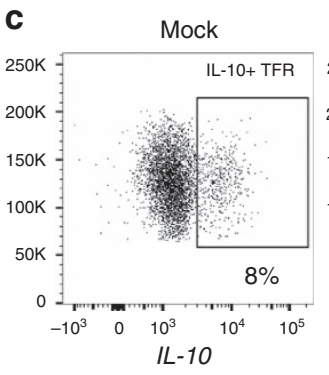
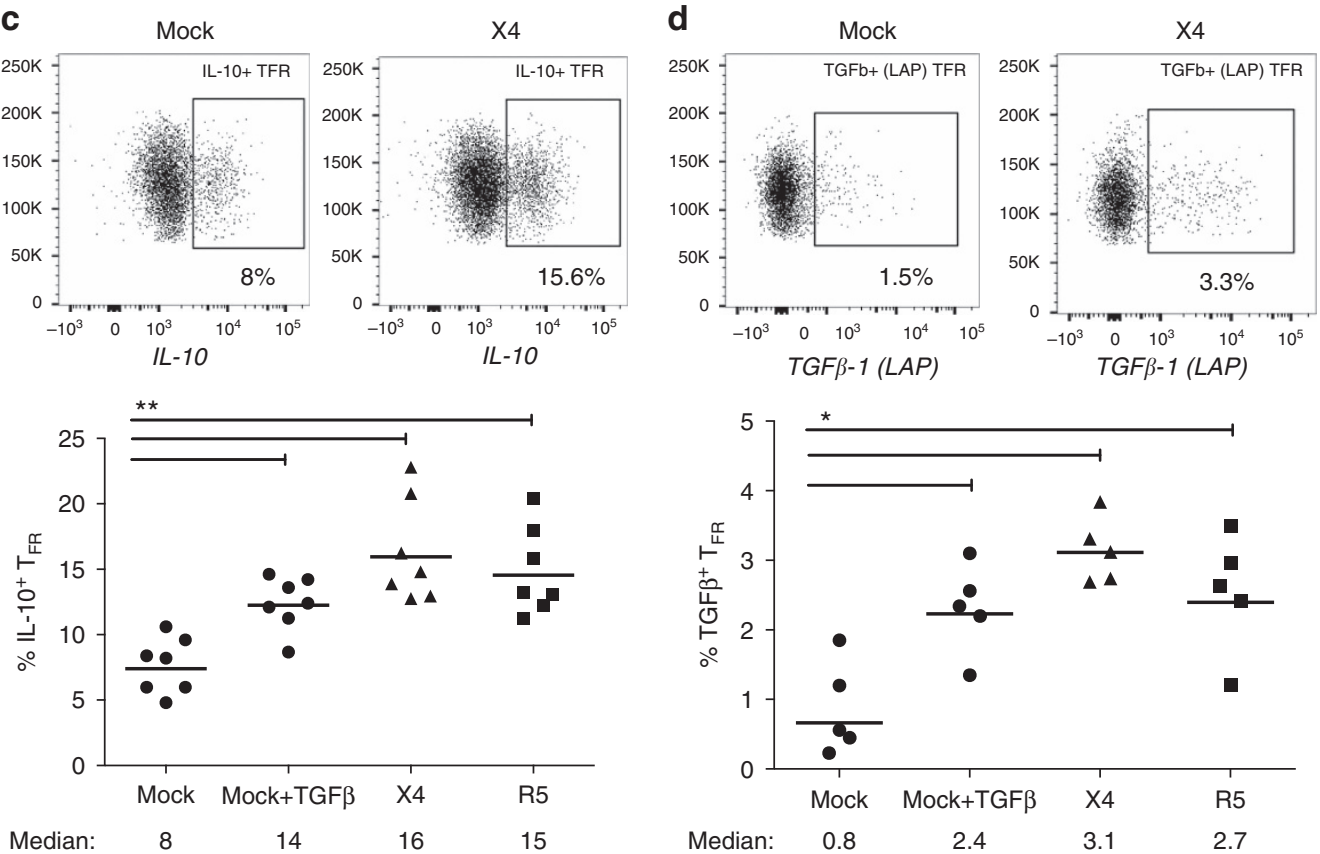

Figure 6 | $\mathbf{T}_{\mathbf{F R}}$ exhibit an enhanced regulatory phenotype in ex vivo HIV infection. Tonsil cells were mock-, X4-, or R5-spinoculated and cultured under experimental conditions as indicated. $T_{F R}$ were then analysed for expression of regulatory receptors and cytokine production by intracellular cytokine staining. (a) Percentage of total (surface and intracellular) $T_{F R}$ CTLA-4 expression $(n=15)$. (b) Percentage of surface $T_{F R} L A G-3$ expression ( $n=8$ ). (c) Production of IL-10 by $T_{F R}(n=7)$. (d) Production of TGF- $\beta-1$ (measured as LAP) by $T_{F R}(n=5)$. The horizontal bars of each graph indicate the median value and are listed where appropriate for clarity. Statistical analyses were performed by Friedman $(\mathbf{a}, \mathbf{b})$ or Mann-Whitney tests $(\mathbf{c}, \mathbf{d})$ and significance is denoted by asterisks where ${ }^{\star} P<0.05,{ }^{\star \star} P<0.01$ and ${ }^{\star \star \star} P<0.001$. 
a

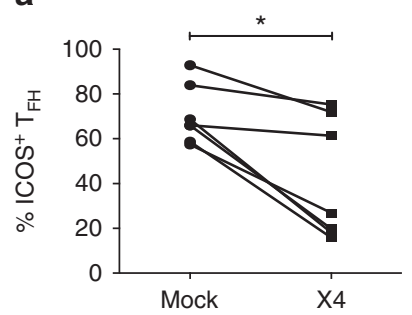

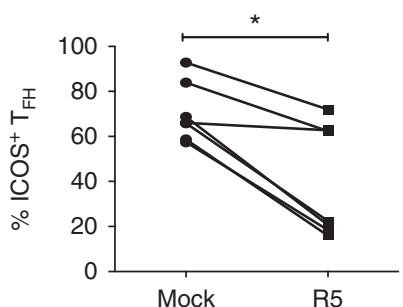

b

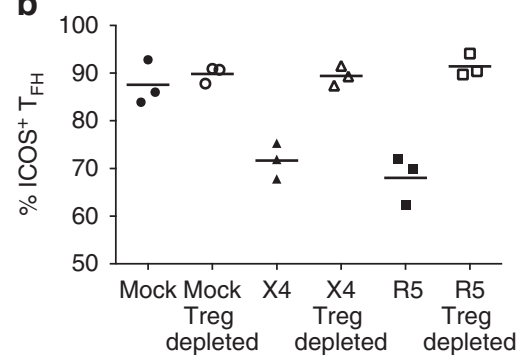

c
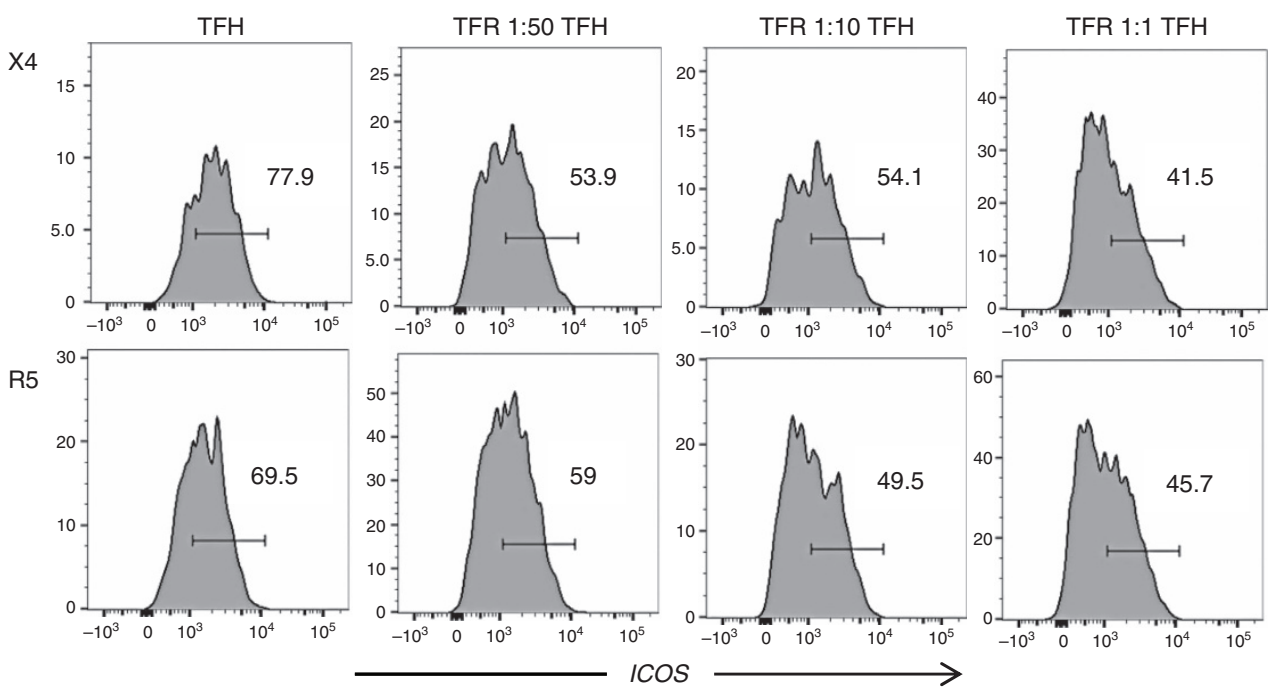

d
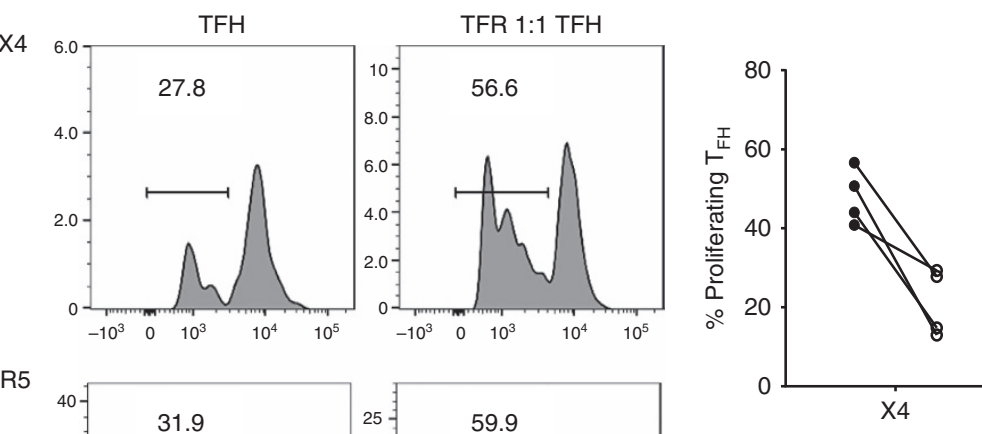

- $\mathrm{T}_{\mathrm{FH}}$

$\theta 1 \mathrm{~T}_{\mathrm{FR}}: 1 \mathrm{~T}_{\mathrm{FH}}$

R5

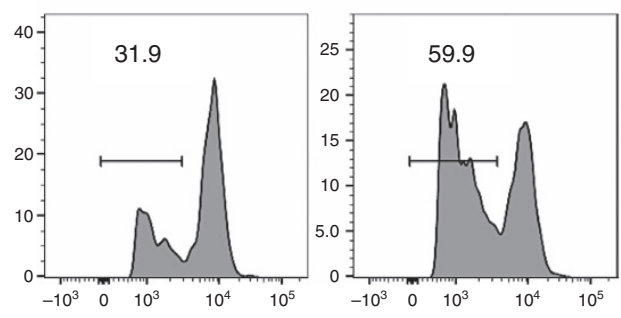

Proliferation dye

Figure 7 | $\mathbf{T}_{\mathbf{F R}}$ impair $\mathbf{T}_{\mathbf{F H}}$ ICOS expression and proliferation. (a) Tonsil $T_{F H}$ were analysed for surface ICOS, following mock-, X4-, or R5-spinoculation $(n=7)$. (b) $C D 25^{+}$regulatory cells were depleted from each culture condition and ICOS expression on $T_{F H}$ was analysed $(n=3)$. (c) Tonsil $T_{F H}$ and $T_{F R}$ were isolated, spinoculated and co-cultured for 2 days at the indicated ratios. Representative images of ICOS expression on $T_{\mathrm{FH}}$ surface are shown $(n=2)$. (d) Tonsil $\mathrm{T}_{\mathrm{FH}}$ were isolated, labelled with efluor 670 proliferation dye, and cultured alone or with an equal number of $\mathrm{T}_{\mathrm{FR}}$. Proliferation was measured by dye dilution $(n=4)$. The horizontal bars of each graph indicate the median value and are listed where appropriate for clarity. Statistical analyses were performed using Friedman nonparametric tests (a) and significance is denoted by asterisks where ${ }^{\star} P<0.05$.

capacity of $\mathrm{T}_{\mathrm{FR}}$ was due to the production of suppressive cytokines, we performed intracellular cytokine assays in the presence of both IL-10- and TGF- $\beta$-neutralizing antibodies. Previous reports show that IL-10 potently blocks IL-4 production $^{44}$, so we specifically addressed IL-21 production by $\mathrm{T}_{\mathrm{FH}}$. Neutralization of IL-10 and TGF- $\beta$ restored some, but not the majority of IL-21 production by $\mathrm{T}_{\mathrm{FH}}$ in the presence of $\mathrm{T}_{\mathrm{FR}}$ (Fig. 8e).

\section{Discussion}

In the present study, we provide a comprehensive analysis of $\mathrm{T}_{\mathrm{FR}}$ in HIV and SIV infection. We show that $\mathrm{T}_{\mathrm{FR}}$ are expanded in 
a

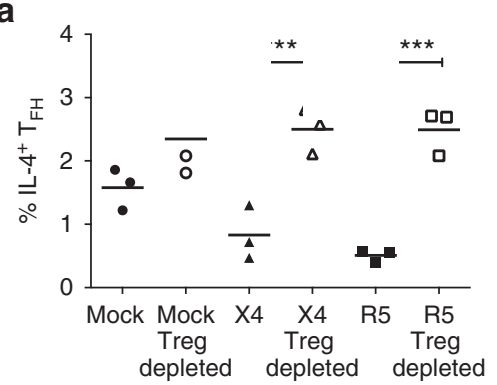

b

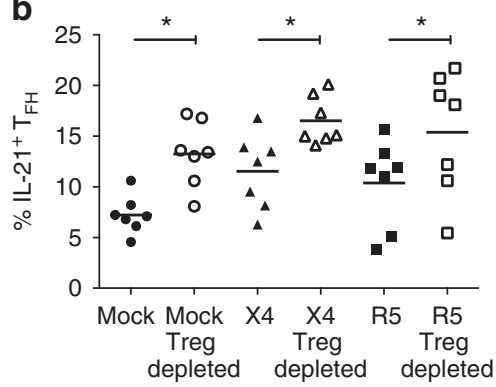

C

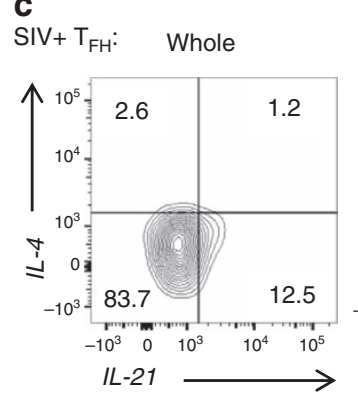

d

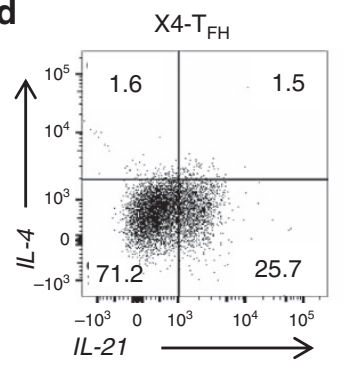

e
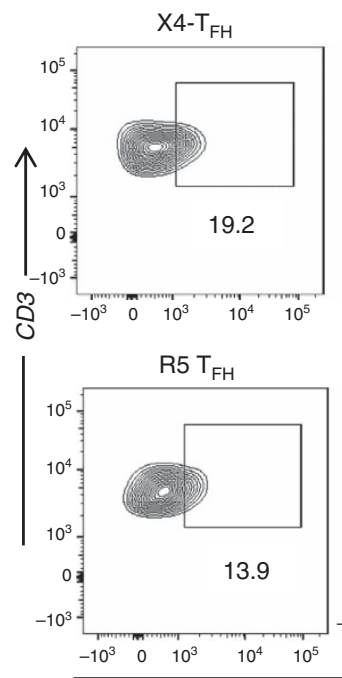
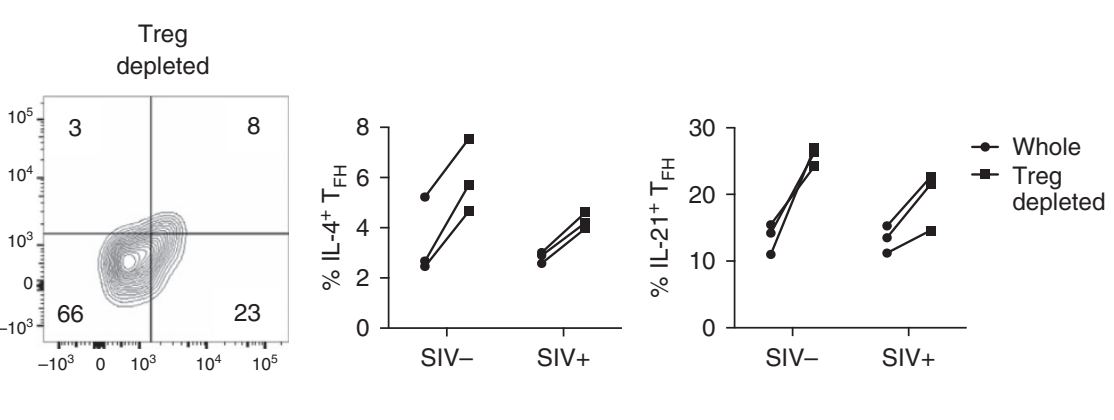
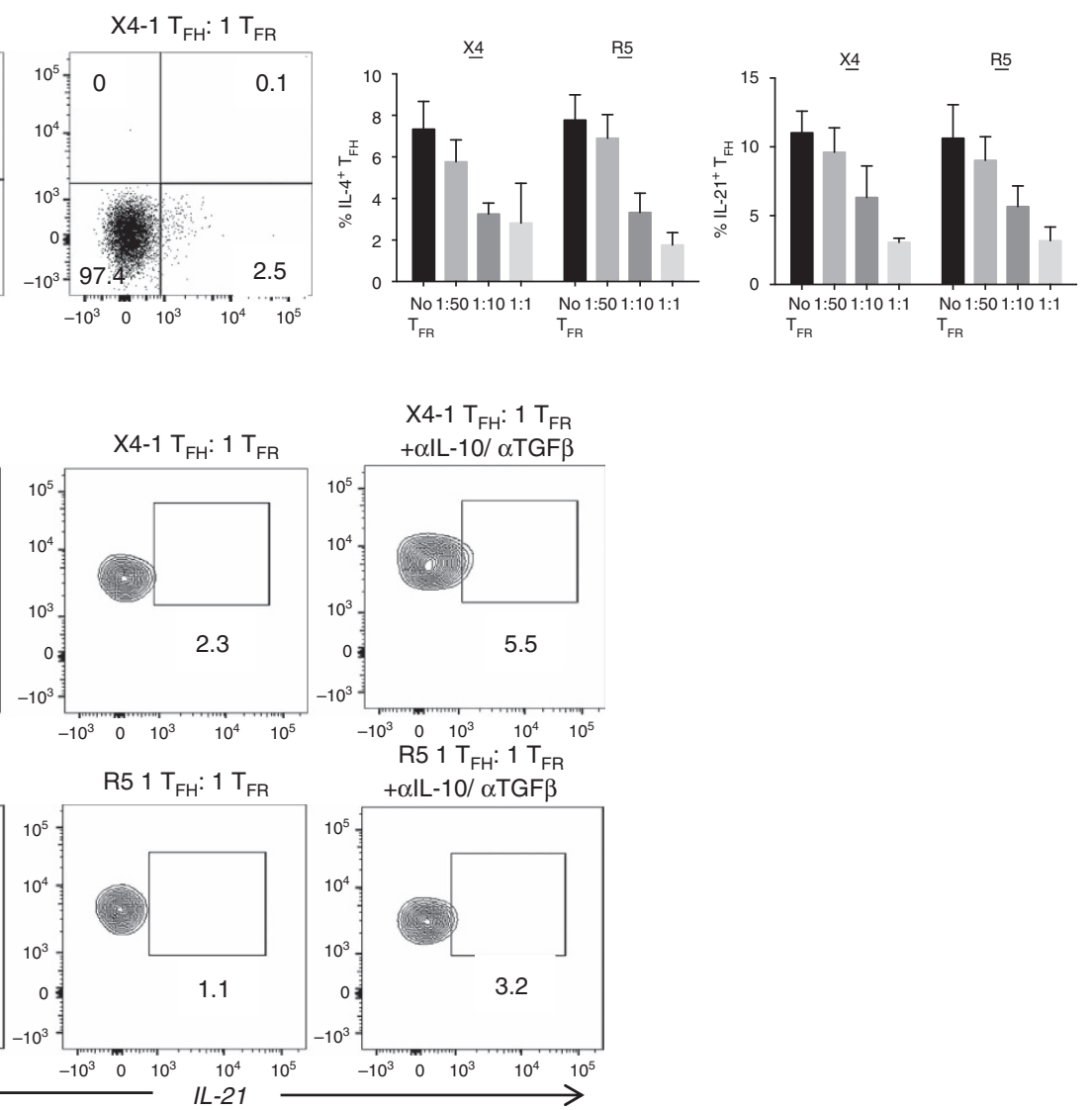

Figure 8 | $\mathbf{T}_{\mathbf{F R}}$ impair $\mathbf{T}_{\mathbf{F H}}$ cytokine production. (a) Tonsil $\mathrm{T}_{\mathrm{FH}}$ were analysed by intracellular cytokine staining for IL-4 and IL-21 production following mock-, X4- or R5-spinoculation. (b) CD25 ${ }^{+}$regulatory cells were depleted before spinoculation and IL-4 $(n=3)$ and IL-21 ( $\left.n=7\right)$ production by $\mathrm{T}_{\mathrm{FH}}$ cells were analysed after 2 days. (c) IL-4 and IL-21 production by $T_{F H}$ were analysed in disaggregated lymph node cells from rhesus macaques with and without CD25-depletion $(n=3)$. (d) Sorted populations of tonsil $T_{F H}$ and $T_{F R}$ were spinoculated, $T_{F R}$ were added back to $T_{F H}$ at an increasing ratio, and $T_{F H}$ production of IL-4 and IL-21 were measured by intracellular cytokine assays at day $2(n=4)$. (e) Sorted tonsil $T_{F H}$ and $T_{F R}$ were cultured for 2 days in the presence of IL-10- and TGF- $\beta$-neutralizing antibodies and $T_{F H}$ production of IL-21 was analysed $(n=2)$. Statistical analyses were performed by Friedman nonparametric tests $(\mathbf{a}, \mathbf{b})$ and significance is denoted by asterisks where ${ }^{\star} P<0.05$ and ${ }^{\star \star \star} P<0.001$. 
secondary lymphoid tissues during both chronic HIV and SIV infection. In addition, we utilize HIV infection ex vivo to show that cell proliferation, regulatory DCs, TGF- $\beta$ signalling, Treg acquisition of CXCR5 and resistance to apoptosis play a role in $\mathrm{T}_{\mathrm{FR}}$ expansion. Finally, we demonstrate that $\mathrm{T}_{\mathrm{FR}}$ are able to inhibit proliferation, ICOS expression and IL-4 and IL-21 production by $\mathrm{T}_{\mathrm{FH}}$. Collectively, these findings reveal that $\mathrm{T}_{\mathrm{FR}}$ play a crucial role in the impairment of $\mathrm{T}_{\mathrm{FH}}$ during HIV and SIV infection.

Although Tregs are diminished in gut-associated lymphoid tissue during HIV infection ${ }^{23}$, prior studies indicate an increase in Tregs in $\mathrm{LNs}^{21,26,45}$. We found that absolute numbers of CD4 ${ }^{+}$Foxp $^{+}$cells in follicles and GCs per average LN crosssection were increased in HIV-infected individuals compared with uninfected individuals. Furthermore, following ex vivo infection of human tonsil cells, we demonstrated that $\mathrm{T}_{\mathrm{FR}}$ increase both proportionally and numerically. As Foxp3 can be transiently upregulated after T-cell activation, we evaluated whether percentages of activated cells were related to Foxp3 expression. Nevertheless, we found no correlation between percentages of activated $\mathrm{LN}$ cells and Tregs and $\mathrm{T}_{\mathrm{FR}}$, and numbers of $\mathrm{GC} \mathrm{T}_{\mathrm{FR}}$ were inversely related to percentages of $\mathrm{HLA}-\mathrm{DR}{ }^{+} \mathrm{CD} 38^{+} \mathrm{CD}^{+}$cells, which is the opposite of what would expect if immune activation was driving Foxp3 expression.

Blockade of the HIV chemokine co-receptors CXCR4 and CCR5 prevented $\mathrm{T}_{\mathrm{FR}}$ expansion in tonsil cells, thus demonstrating that viral entry was necessary to promote expansion. Intriguingly, however, treatment with the integrase inhibitor RAL, which blocks the virus replication cycle after cell entry, largely blunted but did not completely ablate $\mathrm{T}_{\mathrm{FR}}$ expansion. It has recently been demonstrated that many cells during ex vivo HIV infection are abortively infected and only a minority of infected cells are productively infected ${ }^{46}$. Viral sensing mechanisms are important for innate immune cell activation in HIV infection and similar mechanisms may also contribute to $\mathrm{T}_{\mathrm{FR}}$ activation and proliferation. $\mathrm{HIV}$ RNA sensing through internal TLR7 activates $\mathrm{pDC}^{47}$ and TLR7 ligation has been shown to induce CD4 T-cell proliferation $^{48}$. It is possible that HIV sensing by $\mathrm{T}_{\mathrm{FH}}$ or $\mathrm{T}_{\mathrm{FR}}$ contributes to $\mathrm{T}_{\mathrm{FR}}$ expansion and further studies concerning abortive and productive infections are warranted. It has been reported that Treg increases in untreated HIV-infected individuals are diminished after treatment with antiretroviral therapy (ART), but do not normalize ${ }^{49}$. A recent study demonstrated that addition of MVC to ART regimens led to further reductions in Tregs in individuals who were already virologically suppressed ${ }^{50}$. These data, in conjunction with our findings, suggest that in HIV-treated individuals who are fully suppressed on ART regimens that do not include MVC, ongoing nonproductive HIV infection or a low level of HIV replication is occurring resulting in persistent $\mathrm{T}_{\mathrm{FR}}$ expansions that may contribute to immune impairments.

Tonsil $\mathrm{T}_{\mathrm{FR}}$ increased their regulatory capacity during X4 or R5 HIV infection, as evidenced by increased CTLA-4, LAG-3, GITR and galectin-3 expression and production of IL-10 and TGF- $\beta$. In contrast to $\mathrm{T}_{\mathrm{FR}}$ expansions, however, the increased regulatory phenotype was only partially reduced by the addition of AMD and MVC, but fully reduced by CD4 blockade. This finding is consistent with the observation that HIV binding to CD4 molecules enhances their regulatory phenotype and suppressive capabilities $^{31}$. In addition, we found that blockade of TGF- $\beta$ signalling fully inhibited $\mathrm{T}_{\mathrm{FR}}$ regulatory phenotype enhancement during HIV infection. Importantly, we found almost no expression of $\mathrm{PD}-\mathrm{L} 1$ by tonsil $\mathrm{T}_{\mathrm{FR}}$, suggesting that this regulatory molecule does not mediate their effects on $\mathrm{T}_{\mathrm{FH}}$.
Dissecting out the distinct mechanisms responsible for expansion and enhanced regulatory profiles of $\mathrm{T}_{\mathrm{FR}}$ in $\mathrm{HIV}$ infection could identify potential therapeutic targets to suppress excessive $T_{F R}$ activity and could have relevance to host-pathogen interactions in other diseases as well.

We also investigated whether intrinsic characteristics of $\mathrm{T}_{\mathrm{FR}}$ might promote their expansion during HIV infection. We found significant increases in cell proliferation of tonsil $\mathrm{T}_{\mathrm{FR}}$ compared with tonsil $\mathrm{T}_{\mathrm{FH}}$ during both $\mathrm{X} 4$ and $\mathrm{R} 5 \mathrm{HIV}$ infection. It has been well-established that regulatory DCs induce Tregs in HIV infection, and exert this effect in part by low rates of maturation and co-stimulatory molecules ${ }^{39}$ and in part by IDO production $^{40,51}$. The lack of DC maturation observed during HIV infection could contribute to increased Treg and $\mathrm{T}_{\mathrm{FR}}{ }^{52}$. In tonsil cells, we found that myeloid DCs were mostly immature, whereas activated plasmacytoid DCs were significantly increased in HIV infection, which recapitulates previous studies in $\mathrm{HIV}^{39,53,54}$ and $\mathrm{SIV}^{41,42}$ infection in vivo. Tonsil cell cultures also exhibited increased levels of IDO, the IDO upstream activator IFN- $\gamma$ and TGF- $\beta$ during HIV infection. Type I IFNs were not specifically studied in this work, but they have also shown to be increased in tonsil cells infected with NL4-3 HIV ${ }^{55}$. These factors present in the follicular milieu likely contribute to enhanced proliferation and numerical increases of $\mathrm{T}_{\mathrm{FR}}$.

$\mathrm{HIV}$-infected individuals have high rates of overall $\mathrm{CD}_{4}{ }^{+}$ $\mathrm{T}$-cell apoptosis ${ }^{56}$ and higher levels of Annexin- $\mathrm{V}$ binding and caspase- 3 activation in Tregs compared with uninfected controls $^{29}$. We similarly found that total CD3 ${ }^{+} \mathrm{CD}^{-}$cells and Tregs had higher levels of Annexin-V binding in chronically SIV-infected rhesus macaques. Remarkably, however, we found that $\mathrm{T}_{\mathrm{FR}}, \mathrm{GC} \mathrm{T}_{\mathrm{FR}}$ and $\mathrm{GC} \mathrm{T}_{\mathrm{FH}}$ had lower levels of Annexin- $\mathrm{V}$ binding in SIV-infected rhesus macaques compared with uninfected animals. Furthermore, $\mathrm{T}_{\mathrm{FR}}$ and $\mathrm{GC} \mathrm{T}_{\mathrm{FR}}$ had the lowest levels of Annexin-V binding of any subset in SIV-infected macaques, but not in uninfected macaques. These findings imply that regulatory follicular cells may be more resistant to apoptosis than other subsets, which could promote their accumulation. This could explain our observation that lymphoid tissue ratios of $\mathrm{T}_{\mathrm{FR}}$ to $\mathrm{T}_{\mathrm{FH}}$ and $\mathrm{GC} \mathrm{T}_{\mathrm{FR}}$ to $\mathrm{GC} \mathrm{T}_{\mathrm{FH}}$ in chronically SIV-infected rhesus macaques were significantly higher than those from SIV-uninfected animals, but that this phenomenon was not observed in the Treg population as a whole compared with non-Treg $\mathrm{CD} 3{ }^{+} \mathrm{CD} 8^{-}$cells. We recently reported that tonsil follicular $\mathrm{CD}_{4}{ }^{+} \mathrm{T}$ cells have elevated $\mathrm{Bcl}-2$ expression and $\mathrm{Bcl}-2$ is further upregulated on cells that are productively infected with $\mathrm{R} 5$ virus ${ }^{57}$. However, these studies did not discriminate between $\mathrm{T}_{\mathrm{FR}}$ and $\mathrm{T}_{\mathrm{FH}}$ populations. Thus, elevated Bcl-2 expression on $\mathrm{T}_{\mathrm{FR}}$ could be a mechanism that protects $\mathrm{T}_{\mathrm{FR}}$ from apoptosis. The mechanisms of $\mathrm{T}_{\mathrm{FR}}$ apoptosis and how they contribute to $\mathrm{T}_{\mathrm{FR}}$ number warrant further investigation.

In characterizations of $\mathrm{T}_{\mathrm{FR}}$ in mice, it was shown that $\mathrm{T}_{\mathrm{FR}}$ arise from non- $\mathrm{T}_{\mathrm{FH}}$ precursors and express both Blimp-1 and Bcl-6 (refs 14,15). To assess this in humans, we isolated both $\mathrm{T}_{\mathrm{FH}}$ and non-follicular (CXCR5 ${ }^{-}$) subsets from tonsils and looked for alterations in their phenotype. $\mathrm{T}_{\mathrm{FH}}$ did not acquire a $\mathrm{T}_{\mathrm{FR}}$ phenotype, even when provided with exogenous TGF- $\beta$. A small population of $\mathrm{CXCR}^{-}$cells, however, acquired CXCR5 expression and expressed Foxp3. Despite being numerically small, this new $T_{F R}$ population could contribute substantially to increase the $\mathrm{T}_{\mathrm{FR}}$ population. Intriguingly, it was recently shown that $\mathrm{T}_{\mathrm{FH}}$ differentiation and maintenance was optimized by TGF- $\beta$ in combination with $\mathrm{T}_{\mathrm{FH}}$ cytokines IL-12 and IL-23, but naïve $\mathrm{CD}^{+}{ }^{+} \mathrm{T}$ cells cultured with TGF- $\beta$ alone acquired Treg expression profiles while promoting CXCR5 expression ${ }^{58}$. This further supports the notion that the expansions of $\mathrm{T}_{\mathrm{FR}}$ observed 
in our study likely originate from non- $\mathrm{T}_{\mathrm{FH}}$ precursors. We also find that human $\mathrm{T}_{\mathrm{FR}}$ express Bcl-6 and Blimp-1 and neither was altered after HIV spinoculation. However, expression of Bcl-6 by $\mathrm{T}_{\mathrm{FH}}$ was significantly reduced after HIV spinoculation. A more detailed analysis would be valuable to reveal the effects of HIV on both $\mathrm{T}_{\mathrm{FH}}$ and $\mathrm{T}_{\mathrm{FR}}$ transcriptional profiles.

A hallmark of HIV infection is the production of high levels of HIV-specific antibodies that are unable to suppress HIV $^{27}$. HIV-specific neutralizing antibodies are produced in many individuals during HIV infection ${ }^{59}$, however, the virus is able to rapidly mutate and avoid recognition ${ }^{60,61}$. Although broadly neutralizing antibodies (bNabs) are effective in suppressing HIV replication ${ }^{62}$, few people develop bNabs ${ }^{63}$. Whether $\mathrm{T}_{\mathrm{FR}}$ limit the ability of HIV-infected individuals to develop bNabs is an important question. BNabs are characterized by high-affinity maturation rates in GCs, and functional $\mathrm{T}_{\mathrm{FH}}$ are crucial for somatic hypermutation levels of maturing B cells in follicles ${ }^{6}$. The level of bNabs in a cohort of HIV seronegative individuals who received an HIV vaccine positively correlated to functional circulating resting memory $\mathrm{T}_{\mathrm{FH}}{ }^{64}$. We demonstrate that $\mathrm{T}_{\mathrm{FR}}$ inhibit the ability of $\mathrm{T}_{\mathrm{FH}}$ to proliferate, to produce crucial B-cell help cytokines IL-4 and IL-21, and maintain ICOS expression. Whether these factors are key to developing bNabs is of critical importance to address. Apart from direct effects on $\mathrm{T}_{\mathrm{FH}}, \mathrm{T}_{\mathrm{FR}}$ may inhibit bNab production through direct interactions with $\mathrm{B}$ cells, or indirectly by altering the follicle microenvironment or follicular DC network during HIV infection. Thus, understanding the impact of $\mathrm{T}_{\mathrm{FR}}$ on the GC reaction and development of bNabs is complex. These questions cannot be readily addressed within tissue cultures systems, but would be best answered in an interventional study in which $\mathrm{T}_{\mathrm{FR}}$ are manipulated.

The dynamics of GC formation in acutely SIV-infected rhesus macaques were recently characterized ${ }^{65}$. Interestingly, animals with the most impaired GC development experienced the most rapid disease progression. It would be important to evaluate whether a robust $\mathrm{T}_{\mathrm{FR}}$ response correlates with the greatest impairment in GC formation in these animals. Interestingly, Treg-depleted mice infected with influenza had limited GC size and compromised influenza-specific $\mathrm{T}_{\mathrm{FH}}$ responses ${ }^{66}$. One possible explanation is that $\mathrm{T}_{\mathrm{FR}}$ are critical for GC formation and fine-tuning of immune responses during acute infections, but may exert more suppressive responses in chronic disease ${ }^{67}$. It will be important to determine the precise role of $\mathrm{T}_{\mathrm{FR}}$ in $\mathrm{GC}$ development and maintenance during different stages of HIV, as well as in other chronic infections.

$\mathrm{T}_{\mathrm{FR}}$ are emerging as important drivers of GC dynamics. Our findings that $\mathrm{T}_{\mathrm{FR}}$ are expanded during HIV infection and impair $\mathrm{T}_{\mathrm{FH}}$ function have multiple important implications. First, they provide a potential mechanism for the impaired humoral responses observed in untreated HIV-infected individuals, particularly the inability to develop bNabs. Second, they provide a potential explanation for persistent impairments in humoral immunity seen in HIV-infected individuals, despite good virologic suppression on ART that does not contain a CCR5 receptor blocker. They further suggest that prophylactic HIV vaccines should be designed to minimize induction of $\mathrm{T}_{\mathrm{FR}}$, as they could impair development of protective antibody responses. Finally, these studies have implications for diseases and vaccine strategies apart from HIV infection, as it is likely that $\mathrm{T}_{\mathrm{FR}}$ play a key role in immune responses to many infections. Thus, a better understanding of the role of $\mathrm{T}_{\mathrm{FR}}$ in the context of HIV infection can provide important insights into the dynamics of GC responses and humoral immunity during infection and adds a new dimension to the intricacies of vaccine development.

\section{Methods}

Human and rhesus macaque subjects and clinical specimens. Inguinal LNs were obtained by excisional biopsy in an outpatient procedure as previously described $^{4}$ from individuals with documented HIV-1 infection for at least 6 months, who were not receiving ART and had CD4 ${ }^{+}$T-cell counts of $\geq 300$ per $\mathrm{mm}^{3}$. None of these subjects had an opportunistic infection, malignancy or acute illness at the time of LN excision. CD4 ${ }^{+}$T-cell counts ranged from 214 to 1,103 cells per $\mathrm{mm}^{3}$ (median, 478 cells per $\mathrm{mm}^{3}$ ), and plasma viral load ranged from 2.87 to $5.88 \log _{10}$ copies per ml (median, $4.26 \log _{10}$ copies per ml). A total of $10(53 \%)$ of subjects were females, ages ranged from 21 to 50 years (median, 34 years) and 10 (53\%) were white, including 3 Hispanics, and 9 were black (47\%). Inguinal LNs were also obtained from HIV-1-seronegative individuals while they underwent a non-emergent surgical procedure in the groin area. A total of $6(75 \%)$ of seronegative subjects were female, ages ranged from 32 to 71 years (median, 50 years), and 7 (88\%) were white, including 1 Hispanic, and 1 (12\%) was black. Informed consent was obtained from all LN donors. Human tonsils were obtained from the Colorado Children's Hospital (Aurora, CO, USA) following routine tonsillectomy from individuals at low risk for HIV infection. Use of tonsil specimens for these studies was reviewed by the Colorado Multiple Institutional Review Board and determined to not constitute human subjects research, in accordance with guidelines issued by the Office of Human Research Protections (http://www.hhs.gov/ohrp/policy/checklists/decisioncharts.html), and consequently, informed consent was not required. All research involving human subjects conformed to the principles set forth in the Declaration of Helsinki and was approved by the Colorado Multiple Institutional Review Board. LNs and the spleen were obtained from SIVmac239-infected and uninfected Indian rhesus macaques (Macaca mulatta). Animals were infected either intravenously or intrarectally with SIVmac239, and had been infected from 12 to 241 weeks (median, 19.5 weeks) at the time that specimens were obtained. Plasma SIV RNA concentrations ranged from 3.77 to $6.76 \log _{10}$ copies per ml (median, $5.72 \log _{10}$ copies per $\mathrm{ml}$ ), and $\mathrm{CD} 4{ }^{+} \mathrm{T}$ cell counts ranged from 142 to 569 cells per $\mathrm{mm}^{3}$ (median, 348 cells per $\mathrm{mm}^{3}$ ). Of SIV-infected animals, 4 (40\%) were female and they ranged in age from 7 to 17 years (median, 9 years). Of SIV uninfected animals, $2(22 \%)$ were female and they ranged in age from 3 to 23 years (median, 4 years). Animals were housed and cared for in accordance with the American Association for Accreditation of Laboratory Animal Care standards in accredited facilities, and all animal procedures were performed according to protocols approved by the Institutional Animal Care and Use Committees of the Wisconsin National Primate Research Center. Tissues were either shipped overnight on ice in cold RPMI 1640 and disaggregated or disaggregated at the Wisconsin National Primate Research Center and frozen cells shipped on liquid nitrogen to the University of Colorado. Sample sizes in this study were based on availability of specimens and prior experience of the necessary sample size to see anticipated effects.

Quantification of Foxp3 ${ }^{+}$CD4 $^{+}$cells in lymphoid tissues. Six-micrometre frozen sections of LN were thaw mounted onto slides and fixed in 1\% paraformaldehyde (Sigma) in PBS. Two or three sections, at least $60 \mu \mathrm{m}$ apart, were stained and evaluated for each subject. Indirect immunofluorescent staining was performed by first staining with Rabbit anti-IgD (Novus, cat\# NB120-17184, 1:50) and mouse anti-Foxp3 (clone 236A/E7; eBiosciences, cat\#14-4777-82, 1:100) for $1 \mathrm{~h}$ followed by detection with Pacific Blue anti-Rabbit IgG (cat\# P10994, 1:100) and AF488 anti-mouse IgG (cat\#A21200, 1:200; both from Invitrogen) for $30 \mathrm{~min}$. After washing, sections were incubated for an additional hour with Rabbit anti-CD20 (Abcam, cat\# ab27093, 1:400) and Rat anti-CD4 (clone YNB46.1.8; AbD Serotec, cat\# MCA484G, 1:100) followed by detection with AF647 anti-rabbit IgG (Invitrogen, cat\#A21443, 1:200) and AF594 anti-rat IgG (Invitrogen, cat\#A21209, 1:200). Slides were covered with coverslips using SlowFade Gold (Invitrogen). Images of full sections were generated at $\times 60$ using an Olympus VS120 scanner outfitted with an OrcaR2 camera (Olympus). Ten random images were extracted for each section from the main scans and Foxp $3^{+} \mathrm{CD}^{+}$cells per $\mathrm{mm}^{2}$ of total, follicle $\left(\mathrm{CD}_{2} 0^{+}\right)$and $\mathrm{GC}\left(\mathrm{CD} 20^{+} \mathrm{IgD}^{-}\right)$was determined using visual inspection and quantitative image analysis (Qwin Pro 3.4.0, Leica Microsystems). The areas of each LN cross-section, as well as the follicular and GC compartments, were determined by quantitative image analysis and averaged for each subject. The average number of Foxp $3{ }^{+} \mathrm{CD} 4{ }^{+}$cells per LN cross-section and compartment was calculated by multiplying the frequency of Foxp $3^{+} \mathrm{CD} 4{ }^{+}$cells by the average area of the LN, follicle or GC in each subject.

Quantification of activated CD4 ${ }^{+} \mathbf{T}$ cells in human LNs. Disaggregated LN cells $\left(5 \times 10^{6}\right)$ were stained with antibodies to CD3-PEcy5-UCHT1 (BD Biosciences, 555334), CD4-APC-H7-RPAT4 (BD, 560158), CD38-FITC-240742 (Invitrogen, FAB2404F) and HLA-DR-APC-L243 (BD, 340549), evaluated by flow cytometry (LSR II, BD Immunocytometry Systems) and analysed using FlowJo (Tree Star). All antibodies were used at one test per $10^{6}$ cells.

HIV reporter viruses and tonsil infection model. The HIV-1 NL4-3-based CXCR4 (X4)-tropic GFP reporter virus NLENG1-IRES ${ }^{68}$ and the CCR5 (R5)-tropic GFP reporter virus NLYUV3-GFP ${ }^{33}$ were used for tonsil cell infections. Virus stocks were prepared by transfecting $293 \mathrm{~T}$ cells with either X4 or R5 plasmid 
constructs (Effectine, Qiagen) in complete DMEM (DMEM + 10\% FBS, penicillin/ streptomycin and non-essential amino acids), collecting supernatants and spinning at $800 \mathrm{~g}$ to remove debris. Viral stocks were stored at $-80^{\circ} \mathrm{C}$ before use. After disaggregation, $5 \times 10^{6}$ tonsil cells were spinoculated with either GFP reporter virus or a mock spinoculation with an equal volume of complete DMEM for $2 \mathrm{~h}$ at $1,200 \mathrm{~g}$ at room temperature. Cells were washed to remove unbound virus and media, and cultured for 2 days at $37^{\circ} \mathrm{C}$ with $5 \% \mathrm{CO}_{2}$ in RPMI with $10 \% \mathrm{FBS}$, L-glutamine and penicillin/streptomycin (R10) at a density of $1.5 \times 10^{6}$ cells per ml. To block viral entry, tonsil cells were incubated in $\mathrm{R} 10$ at $37^{\circ} \mathrm{C}$ with $5 \% \mathrm{CO}_{2}$ for $1 \mathrm{~h}$ with $2 \mu \mathrm{M}$ MVC, $200 \mu \mathrm{M}$ bicyclam or $10 \mathrm{ng} \mathrm{ml}^{-1}$ of anti-human CD4 (BioLegend, 300515). To block HIV integration, tonsil cells were incubated with $10 \mu \mathrm{M}$ of the integrase inhibitor RAL in R10 for $1 \mathrm{~h}$ before spinoculation and included in the culture for 2 days. To block TGF- $\beta$ signalling, $2 \mu \mathrm{g} \mathrm{ml}{ }^{-1}$ of anti-human TGF- $\beta$ (BioLegend, 521703) was included for the duration of the culture. Exogenous TGF- $\beta$ (Sigma, T7039) was added at a concentration of $100 \mathrm{ng} \mathrm{ml}^{-1}$ to induce Treg and $\mathrm{T}_{\mathrm{FR}}$ in selected cultures as a positive control. At the end of culture, the cell supernatants were collected, centrifuged at $6,800 \mathrm{~g}$ to remove debris and frozen at $-80^{\circ} \mathrm{C}$ for subsequent ELISA analysis. Cells were collected and immediately processed for analysis by flow cytometry.

Flow cytometry analysis of T cells and DCs. Cells were blocked for 20 min with $2 \% \mathrm{BSA}$ in PBS at $4{ }^{\circ} \mathrm{C}$ and then stained for $30 \mathrm{~min}$ at $4{ }^{\circ} \mathrm{C}$ in the dark. For T-cell phenotyping, the following anti-human-conjugated antibodies were used: CD3-APCCy7-UCHT1 (Tonbo, 25-0038), CD8-eVolve605-RPA-T8 (eBioscience, 83-0088), CD25-PECy7-BC96 (Tonbo, 60-0259), CXCR5-PE-MU5UBEE (eBioscience, 18-9185), CD127-Pacific Blue-A1095 (BioLegend, 351306), ICOS-ISA-3 (PECy7 or APC; BioLegend, 313520, 313510), PD-1-APC-MIH4 (eBioscience, 17-9969) or PD-1-APC-EH12.2H7 (BioLegend, 329908), Bcl6-PerCPCy5.5 - K112-91 (BD, 562198), Blimp1-646702 (R\&D IC36081A), CTLA-4-PerCPeFluor710-14D3 (eBioscience, 46-1529), GITR-PE-eBioAITR (eBioscience, 12-5875), LAG-3-APC-3DS223H (eBioscience, 17-2239), Galectin3 - AF647-M3/38 (BioLegend, 125408) and Galectin-9 - PerCPCy5.5-9M1-3 (BioLegend, 348910). The same panel was used for rhesus macaque cell staining with the single exception of CD3-APCCy7-SP34-2 (BD, 557757). Foxp3 expression in $\mathrm{CD} 25^{+} \mathrm{CD} 127^{-}$cells was confirmed using Foxp3-PE-PHC1O1 and the Foxp3/ Transcription factor permeabilization kit (eBioscience, 72-5776) according to the manufacturers' protocols. For DC phenotyping, the following anti-human-conjugated antibodies were used: CD14-eFluor450-61D3 (eBioscience, 8048-0149), CD1c-PECy7-L161 (eBioscience, 25-0015), CD3-APCCy7-UCHT1 (Tonbo, 250038), CD11c-PE-3.9 (eBioscience, 12-0116), CD19-AF700-HIB19 (BioLegend, 302226), CD83-BV510-HB15e (BD, 563223), CD123-BV605-7G3 (BD, 564197), DC-SIGN-PerCPCy5.5-eB-h209 (eBioscience, 45-2099) and HLA-DR-APC-L243 (BD, 340691). All analyses were performed on Aqua LIVE/DEAD (Molecular Probes, L34957) or Ghost Dye 510 (Tonbo, 13-0870) negative cells. Fresh human tonsil cells were typically $70-90 \%$ viable after culture and cryopreserved rhesus macaque cells ranged from 40 to $80 \%$ viability after freeze/thaw. All antibodies were used at one test per $10^{6}$ cells. Cells were fixed with $2 \%$ paraformaldehyde. Data were acquired on a custom LSR II flow cytometer (Serial \# H47100196, BD Immunocytometry System) with BDFACS Diva (v6.1) and with a configuration of six filters ( 755LP, 685LP, 670LP, 635LP, 600LP, 550LP and 505LP) on a blue laser $(488 \mathrm{~nm})$, three filters (595LP, 505LP and 450/50) on a violet laser $(405 \mathrm{~nm})$ and three filters $(755 \mathrm{LP}, 685 \mathrm{LP}$ and $670 / 30)$ on a red laser $(633 \mathrm{~nm})$. FCS files were analysed using FlowJo (v10.7, Tree Star).

$\mathbf{T}_{\mathrm{FR}}$ counts and cell death time course. For the 5-day time course, cells were prepared and cultured as above with the exception of addition of $10 \mathrm{U} \mathrm{ml}^{-1}$ of IL-2 to culture. Cells were harvested and analysed each day for cell death and total counts. Cell counts were performed using CountBright absolute counting beads (Molecular Probes, C36950) according to the manufacturers' instructions. Briefly, all cell fractions were resuspended in $400 \mu \mathrm{l}$ of buffer and $50 \mu \mathrm{l}$ of beads were added. At least 1,000 bead events were collected for each sample and the number of cells per $\mu \mathrm{l}$ was calculated based on the fixed bead concentration supplied by the manufacturer. In addition, a separate analysis of the same cell fractions was performed using the Annexin-V PE apoptosis detection kit (eBioscience, 88-8102) according to the manufacturers' instructions. Each T-cell population was analysed based on early apoptosis (Annexin-V staining), late or advanced apoptosis (Annexin-V and PI) and necrosis (PI).

ELISAs. Cell culture supernatants were measured for TGF- $\beta-1$ secretion (R\&D Systems, DB100B), IL-10 (R\&D Systems, DB1000B), IFNy (R\&D Systems, DIF50) and IDO (Cloud Clone SEB547Hu) according to the manufacturers' instructions. Absorbance values were converted to protein levels using a protein standard dilution. Cell lysates as well as culture supernatants were evaluated by IDO ELISA.

Intracellular cytokine staining assays. After 2 days of culture, tonsil cells were stimulated with $50 \mathrm{ng} \mathrm{ml}^{-1}$ of PMA (Sigma, P8139) and $1 \mu \mathrm{g} \mathrm{ml}^{-1}$ of ionomycin (Sigma, I3909) in the presence of protein transport inhibitor containing monensin (BD GolgiStop) for $5 \mathrm{~h}$. Cryopreserved rhesus macaque cells were rested for $24 \mathrm{~h}$ (viability $40-80 \%$ ) in R10 and then stimulated in the same manner for $5 \mathrm{~h}$. Cells were then harvested, blocked and stained for surface markers as above, and then fixed and permeabilized using BD CytoFix/Cytoperm kit (554714) according to the manufacturer's instructions. Cells were then stained at $4{ }^{\circ} \mathrm{C}$ for $30 \mathrm{~min}$ with IL-4-PercpCy5.5-8D4-8 (BD, 561234), IL-10-eFluor450-JES3-9D7 (eBioscience, 48-7108), IL-21-AF647-3A3-N2.1 (BD, 560493) and TGF- $\beta$-1-PE(LAP)-27232 (R\&D, FAB2463P). All antibodies were used at one test per $10^{6}$ cells. All cytokine analyses were normalized to a mock-spinoculated control that received monensin but was unstimulated.

CD25-depletion cultures. $\mathrm{CD} 25^{+}$cells were depleted immediately after tonsil cell disaggregation using a FITC-positive selection kit (StemCell, 18558) and CD25-FITC-BC96 (BioLegend, 302604). Cells were spinoculated and cultured as described above. Mock- and HIV-spinoculated cultures from non-depleted cells were run in parallel with each experiment. After 2 days of culture, cells were analysed for $\mathrm{T}_{\mathrm{FH}}$ and $\mathrm{T}_{\mathrm{FR}}$ phenotypes by flow cytometry as described above. A subset of $\mathrm{CD} 25^{+}$-depleted cells was analysed to confirm the absence of Foxp3 ${ }^{+}$cells.

BrdU ex vivo proliferation assay. Ex vivo BrdU labelling was performed using a flow cytometry kit (eBioscience, 8817-6600) according to the manufacturers' instructions. For BrdU labelling of primary cells in culture, a range of incubation times for BrdU uptake were tested and $24 \mathrm{~h}$ was found to be the optimal timepoint. Tonsil cells were spinoculated and cultured as above and labelled with $10 \mu \mathrm{M}$ of BrdU for $24 \mathrm{~h}$ before analysis. After 2 days of culture, cells were collected, stained with surface antigens, fixed and permeabilized and treated with DNase I to allow BrdU antibody binding.

Cell sorting and $T_{F R} / T_{F H}$ co-culture. Disaggregated tonsil cells were sorted using a MoFlo Astrios EQ. Cells were sorted into non-follicular (CD3 $\left.{ }^{+} \mathrm{CD} 8-\mathrm{CXCR} 5^{-}\right)$, $\mathrm{T}_{\mathrm{FH}}\left(\mathrm{CD} 3{ }^{+} \mathrm{CD} 8\right.$-CXCR5 $\left.{ }^{+} \mathrm{CD}_{25}{ }^{-}\right)$and $\mathrm{T}_{\mathrm{FR}}\left(\mathrm{CD} 3^{+} \mathrm{CD} 8\right.$-CXCR5 $\left.{ }^{+} \mathrm{CD} 25^{\mathrm{hi}}\right)$ populations. A subset of non-follicular and $\mathrm{T}_{\mathrm{FH}}$ cells were cultured either without treatment or with $100 \mathrm{ng} \mathrm{ml}^{-1}$ of exogenous TGF- $\beta$ to analyse whether $\mathrm{T}_{\mathrm{FH}}$ convert to $\mathrm{T}_{\mathrm{FR}}$. After sorting, $\mathrm{T}_{\mathrm{FH}}$ and $\mathrm{T}_{\mathrm{FR}}$ were spinoculated with $\mathrm{X} 4$ or R5 HIV GFP reporter viruses. $\mathrm{T}_{\mathrm{FH}}$ were then seeded at a set number of $1 \times 10^{5}$ cells in a 24-well plate and $\mathrm{T}_{\mathrm{FR}}$ were added at ratios of 1:1, 1:10 and 1:50. After 2 days, cells were stimulated to measure IL-4 and IL-21 by ICS or left unstimulated to measure ICOS expression. In select experiments, $\mathrm{T}_{\mathrm{FH}}$ and $\mathrm{T}_{\mathrm{FR}}$ were co-cultured in the presence of neutralizing antibodies to IL-10 $\left(1 \mu \mathrm{g} \mathrm{ml}^{-1}\right.$; BioLegend, 501406) and TGF- $\beta\left(1 \mu \mathrm{g} \mathrm{ml}^{-1}\right.$, BioLegend, 521704).

Proliferation assays. $\mathrm{T}_{\mathrm{FH}}\left(\mathrm{CD} 3{ }^{+} \mathrm{CD} 8\right.$-CXCR5 $\left.{ }^{+} \mathrm{CD} 25^{-}\right)$were sorted and stained with proliferation dye (Cell Proliferation Dye eFluor670, eBioscience, 65-0840) at a concentration of $0.5 \mu \mathrm{M}$. In a 96-well plate, pre-coated with $5 \mu \mathrm{g} \mathrm{ml}^{-1}$ anti-CD3 (Tonbo, 40-0037) in PBS at $37^{\circ} \mathrm{C}$ for $2 \mathrm{~h}, 10^{4} \mathrm{~T}_{\mathrm{FH}}$ per well were cultured for 4 days in $200 \mu \mathrm{l} \mathrm{R} 10$ containing $2 \mu \mathrm{g} \mathrm{ml}^{-1}$ anti-CD28 (Tonbo, 40-0289) and $10 \mathrm{U} \mathrm{ml}^{-1} \mathrm{IL}-2$ with an equal number of sorted $\mathrm{T}_{\mathrm{FR}}\left(\mathrm{CD} 3{ }^{+} \mathrm{CD} 8\right.$ $\mathrm{CXCR}^{+} \mathrm{CD} 25^{+} \mathrm{CD} 127^{-}$) or alone. At day 4, cells were stained with viability dye (Ghost V450, Tonbo, 13-0863) and analysed by flow cytometry.

Statistical analysis. Comparisons of infected and seronegative human LNs or rhesus macaque spleen or LNs were performed by non-parametric Mann-Whitney tests. Comparisons of tonsil cultures were performed by unpaired Mann-Whitney or Friedman nonparametric tests. In direct comparisons of paired data, a paired Wilcoxon ranked sums test was performed to compare the two group medians of interest. Significance is denoted in each figure by asterisks, as ${ }^{\star} P<0.05,{ }^{* \star} P<0.01$ and ${ }^{* *} P<0.001$.

\section{References}

1. Chomont, N. et al. HIV reservoir size and persistence are driven by T cell survival and homeostatic proliferation. Nature Med. 15, 893-900 (2009).

2. Schacker, T. et al. Rapid accumulation of human immunodeficiency virus (HIV) in lymphatic tissue reservoirs during acute and early HIV infection: implications for timing of antiretroviral therapy. J. Infect. Dis. 181, 354-357 (2000).

3. Perreau, M. et al. Follicular helper $\mathrm{T}$ cells serve as the major $\mathrm{CD} 4 \mathrm{~T}$ cell compartment for HIV-1 infection, replication, and production. J. Exp. Med. 210, 143-156 (2013)

4. Folkvord, J. M., Armon, C. \& Connick, E. Lymphoid follicles are sites of heightened human immunodeficiency virus type 1 (HIV-1) replication and reduced antiretroviral effector mechanisms. AIDS Res. Hum. Retroviruses 21, 363-370 (2005).

5. Pantaleo, G. et al. Lymphoid organs function as major reservoirs for human immunodeficiency virus. Proc. Natl Acad. Sci. USA 88, 9838-9842 (1991)

6. Crotty, S. Follicular helper CD4 T cells (Tfh). Annu. Rev. Immunol. 29, 621-663 (2011). 
7. Chtanova, T. et al. T follicular helper cells express a distinctive transcriptional profile, reflecting their role as non-Th1/Th2 effector cells that provide help for B cells. J. Immunol. 173, 68-78 (2004).

8. Choi, Y. S. et al. ICOS receptor instructs T follicular helper cell versus effector cell differentiation via induction of the transcriptional repressor Bcl6. Immunity 34, 932-946 (2011).

9. Linterman, M. A. et al. IL-21 acts directly on B cells to regulate Bcl-6 expression and germinal center responses. J. Exp. Med. 207, 353-363 (2010).

10. Eto, D. et al. IL-21 and IL-6 are critical for different aspects of B cell immunity and redundantly induce optimal follicular helper CD4 T cell (Tfh) differentiation. PLoS ONE 6, e17739 (2011).

11. Lindqvist, M. et al. Expansion of HIV-specific T follicular helper cells in chronic HIV infection. J. Clin. Invest. 122, 3271-3280 (2012).

12. Petrovas, C. et al. CD4 T follicular helper cell dynamics during SIV infection. J. Clin. Invest. 122, 3281-3294 (2012).

13. Cubas, R. A. et al. Inadequate $T$ follicular cell help impairs B cell immunity during HIV infection. Nature Med. 19, 494-499 (2013).

14. Chung, Y. et al. Follicular regulatory T cells expressing Foxp3 and Bcl-6 suppress germinal center reactions. Nature Med. 17, 983-988 (2011).

15. Linterman, M. A. et al. Foxp3 ${ }^{+}$follicular regulatory $\mathrm{T}$ cells control the germinal center response. Nature Med. 17, 975-982 (2011).

16. Wollenberg, I. et al. Regulation of the germinal center reaction by Foxp $3^{+}$ follicular regulatory T cells. J. Immunol. 187, 4553-4560 (2011).

17. Card, C. M. et al. Decreased immune activation in resistance to HIV-1 infection is associated with an elevated frequency of $\mathrm{CD} 4{ }^{+} \mathrm{CD} 25^{+} \mathrm{FOXP} 3{ }^{+}$regulatory T cells. J. Infect. Dis. 199, 1318-1322 (2009).

18. Kinter, A. L. et al. $\mathrm{CD} 25^{+} \mathrm{CD} 4{ }^{+}$regulatory $\mathrm{T}$ cells from the peripheral blood of asymptomatic HIV-infected individuals regulate $\mathrm{CD} 4{ }^{+}$and $\mathrm{CD} 8{ }^{+}$ $\mathrm{HIV}$-specific T cell immune responses in vitro and are associated with favorable clinical markers of disease status. J. Exp. Med. 200, 331-343 (2004).

19. Lim, A. et al. Proportions of circulating T cells with a regulatory cell phenotype increase with HIV-associated immune activation and remain high on antiretroviral therapy. AIDS 21, 1525-1534 (2007).

20. Suchard, M. S. et al. FOXP3 expression is upregulated in $\mathrm{CD}^{+}{ }^{+} \mathrm{T}$ cells in progressive HIV-1 infection and is a marker of disease severity. PLOS ONE 5, e11762 (2010)

21. Weiss, L. et al. Human immunodeficiency virus-driven expansion of CD4 ${ }^{+}$ $\mathrm{CD} 25^{+}$regulatory $\mathrm{T}$ cells, which suppress HIV-specific CD4 T-cell responses in HIV-infected patients. Blood 104, 3249-3256 (2004).

22. Epple, H.-J. et al. Mucosal but not peripheral FOXP3 ${ }^{+}$regulatory $\mathrm{T}$ cells are highly increased in untreated HIV infection and normalize after suppressive HAART. Blood 108, 3072-3078 (2006).

23. Angin, M. et al. Preserved function of regulatory T cells in chronic HIV-1 infection despite decreased numbers in blood and tissue. J. Infect. Dis. 205, 1495-1500 (2012).

24. Eggena, M. P. et al. Depletion of regulatory T cells in HIV infection is associated with immune activation. J. Immunol. 174, 4407-4414 (2005).

25. Montes, M. et al. Foxp3 ${ }^{+}$regulatory T cells in antiretroviral-naive HIV patients. AIDS 20, 1669-1671 (2006).

26. Andersson, J. et al. Cutting edge: the prevalence of regulatory $\mathrm{T}$ cells in lymphoid tissue is correlated with viral load in HIV-infected patients. J. Immunol. 174, 3143-3147 (2005).

27. Estes, J. D. et al. Premature induction of an immunosuppressive regulatory $\mathrm{T}$ cell response during acute simian immunodeficiency virus infection. J. Infect. Dis. 193, 703-712 (2006).

28. Nilsson, J. et al. HIV-1-driven regulatory T-cell accumulation in lymphoid tissues is associated with disease progression in HIV/AIDS. Blood 108, 3808-3817 (2006).

29. Xing, S. et al. Increased turnover of FoxP3high regulatory $\mathrm{T}$ cells is associated with hyperactivation and disease progression of chronic HIV-1 infection. J. Acquir. Immune Defic. Syndr. 54, 455-462 (2010).

30. Angin, M. et al. HIV-1 infection impairs regulatory T-cell suppressive capacity on a per-cell basis. J. Infect. Dis. 15, 899-903 (2014)

31. Ji, J. \& Cloyd, M. W. HIV-1 binding to CD4 on $\mathrm{CD} 4{ }^{+} \mathrm{CD} 25^{+}$regulatory T cells enhances their suppressive function and induces them to home to, and accumulate in, peripheral and mucosal lymphoid tissues: an additional mechanism of immunosuppression. Int. Immunol. 21, 283-294 (2009).

32. Imamichi, H. \& Lane, H. C. Regulatory T cells in HIV-1 infection: the good, the bad, and the ugly. J. Infect. Dis. 205, 1479-1482 (2012).

33. Meditz, A. L. et al. HLA-DR ${ }^{+} \mathrm{CD} 38^{+} \mathrm{CD} 4{ }^{+} \mathrm{T}$ lymphocytes have elevated CCR5 expression and produce the majority of R5-tropic HIV-1 RNA In Vivo. J. Virol. 85, 10189-10200 (2011)

34. Shen, L.-S. et al. CD4 (+) CD25 (+) CD127 (low/ - ) regulatory T cells express Foxp3 and suppress effector $\mathrm{T}$ cell proliferation and contribute to gastric cancers progression. Clin. Immunol. 131, 109-118 (2009).

35. Seddiki, N. et al. Expression of interleukin (IL)-2 and IL-7 receptors discriminates between human regulatory and activated T cells. J. Exp. Med. 203, 1693-1700 (2006).
36. Hartigan-O'Connor, D. J., Poon, C., Sinclair, E. \& McCune, J. M. Human $\mathrm{CD}^{+}$regulatory $\mathrm{T}$ cells express lower levels of the IL-7 receptor alpha chain (CD127), allowing consistent identification and sorting of live cells. J. Immunol. Methods 319, 41-52 (2007).

37. Chen, W. et al. Conversion of peripheral $\mathrm{CD} 4{ }^{+} \mathrm{CD} 25^{-}$naive $\mathrm{T}$ cells to $\mathrm{CD} 4{ }^{+}$ $\mathrm{CD} 25^{+}$regulatory $\mathrm{T}$ cells by TGF- $\beta$ induction of transcription factor Foxp3. J. Exp. Med. 198, 1875-1886 (2003).

38. Lanzavecchia, A. \& Sallusto, F. Regulation of T cell immunity by dendritic cells. Cell 106, 263-266 (2001).

39. Dillon, S. M. et al. Plasmacytoid and myeloid dendritic cells with a partial activation phenotype accumulate in lymphoid tissue during asymptomatic, chronic Human Immunodeficiency Virus Type 1 infection. J. Acquir. Immune Defic. Syndr. 48, 1-12 (2008).

40. Boasso, A. et al. HIV inhibits $\mathrm{CD} 4{ }^{+}$T-cell proliferation by inducing indoleamine 2, 3-dioxygenase in plasmacytoid dendritic cells. Blood 109, 3351-3359 (2007).

41. Presicce, P., Shaw, J. M., Miller, C. J., Shacklett, B. L. \& Chougnet, C. A. Myeloid dendritic cells isolated from tissues of SIV-infected Rhesus macaques promote the induction of regulatory T-cells. AIDS 26, 263 (2012).

42. Boasso, A. et al. Regulatory T-cell markers, indoleamine 2, 3-dioxygenase, and virus levels in spleen and gut during progressive simian immunodeficiency virus infection. J. Virol. 81, 11593-11603 (2007).

43. Vignali, D. A., Collison, L. W. \& Workman, C. J. How regulatory T cells work. Nature Rev. Immunol. 8, 523-532 (2008).

44. Ng, T. S. et al. Regulation of adaptive immunity; the role of interleukin-10. Front. Immunol. 4, 129 (2013).

45. Kinter, A. et al. Suppression of HIV-specific T cell activity by lymph node $\mathrm{CD}_{25}{ }^{+}$regulatory T cells from HIV-infected individuals. Proc. Natl Acad. Sci. USA 104, 3390-3395 (2007).

46. Doitsh, G. et al. Abortive HIV infection mediates CD4 T cell depletion and inflammation in human lymphoid tissue. Cell 143, 789-801 (2010).

47. Beignon, A.-S. et al. Endocytosis of HIV-1 activates plasmacytoid dendritic cells via Toll-like receptor-viral RNA interactions. J. Clin. Invest. 115, 3265 (2005).

48. Caron, G. et al. Direct stimulation of human T cells via TLR5 and TLR7/8: flagellin and R-848 up-regulate proliferation and IFN- $\gamma$ production by memory $\mathrm{CD}^{+} \mathrm{T}$ cells. J. Immunol. 175, 1551-1557 (2005).

49. Fellay, J. et al. Response to antiretroviral treatment in HIV-1-infected individuals with allelic variants of the multidrug resistance transporter 1 : a pharmacogenetics study. Lancet 359, 30-36 (2002).

50. Pozo-Balado, M. M. et al. Maraviroc reduces the regulatory T-cell frequency in antiretroviral-naive HIV-infected subjects. J. Infect. Dis. 210, 890-898 (2014).

51. Manches, O. et al. HIV-activated human plasmacytoid DCs induce Tregs through an indoleamine 2, 3-dioxygenase-dependent mechanism. J. Clin. Invest. 118, 3431-3439 (2008).

52. Granelli-Piperno, A., Golebiowska, A., Trumpfheller, C., Siegal, F. P. \& Steinman, R. M. HIV-1-infected monocyte-derived dendritic cells do not undergo maturation but can elicit IL-10 production and T cell regulation. Proc. Natl Acad. Sci. USA 101, 7669-7674 (2004).

53. Favre, D. et al. Tryptophan catabolism by indoleamine 2, 3-dioxygenase 1 alters the balance of TH17 to regulatory T cells in HIV disease. Sci. Transl. Med. 2, 32ra36-32ra36 (2010).

54. Krathwohl, M. D., Schacker, T. W. \& Anderson, J. L. Abnormal presence of semimature dendritic cells that induce regulatory T cells in HIV-infected subjects. J. Infect. Dis. 193, 494-504 (2006).

55. Audige, A. et al. Anti-HIV state but not apoptosis depends on IFN signature in CD4 ${ }^{+}$T cells. J. Immunol. 177, 6227-6237 (2006).

56. Gougeon, M.-L. et al. Programmed cell death in peripheral lymphocytes from HIV-infected persons: increased susceptibility to apoptosis of CD4 and CD8 T cells correlates with lymphocyte activation and with disease progression. J. Immunol. 156, 3509-3520 (1996).

57. Haas, M. K., Levy, D. N., Folkvord, J. M. \& Connick, E. Distinct patterns of Bcl-2 expression occur in R5-and X4-tropic HIV-1-producing lymphoid tissue cells infected ex vivo. AIDS Res. Hum. Retroviruses 31, 298-304 (2014).

58. Schmitt, N. et al. The cytokine TGF-[beta] co-opts signaling via STAT3-STAT4 to promote the differentiation of human TFH cells. Nat. Immunol. 15, 856-865 (2014).

59. Shibata, R. et al. Neutralizing antibody directed against the HIV-1 envelope glycoprotein can completely block HIV-1/SIV chimeric virus infections of macaque monkeys. Nature Med. 5, 204-210 (1999).

60. Wei, X. et al. Antibody neutralization and escape by HIV-1. Nature 422, 307-312 (2003).

61. Richman, D. D., Wrin, T., Little, S. J. \& Petropoulos, C. J. Rapid evolution of the neutralizing antibody response to HIV type 1 infection. Proc. Natl Acad. Sci. USA 100, 4144-4149 (2003).

62. Haynes, B. F. \& Montefiori, D. C. Aiming to induce broadly reactive neutralizing antibody responses with HIV-1 vaccine candidates Expert Rev. Vaccines 5, 579-595 (2006). 
63. Binley, J. M. et al. Comprehensive cross-clade neutralization analysis of a panel of anti-human immunodeficiency virus type 1 monoclonal antibodies. J. Virol. 78, 13232-13252 (2004).

64. Locci, M. et al. Human circulating PD- ${ }^{+} \mathrm{CXCR}^{-} \mathrm{CXCR}^{+}$memory Tfh cells are highly functional and correlate with broadly neutralizing HIV antibody responses. Immunity 39, 758-769 (2013).

65. Hong, J. J., Amancha, P. K., Rogers, K., Ansari, A. A. \& Villinger, F. Spatial alterations between $\mathrm{CD} 4{ }^{+} \mathrm{T}$ follicular helper, B, and CD8 ${ }^{+} \mathrm{T}$ cells during simian immunodeficiency virus infection: T/B cell homeostasis, activation, and potential mechanism for viral escape. J. Immunol. $\mathbf{1 8 8}$, 3247-3256 (2012)

66. León, B., Bradley, J. E., Lund, F. E., Randall, T. D. \& Ballesteros-Tato, A. FoxP3 ${ }^{+}$ regulatory $\mathrm{T}$ cells promote influenza-specific $\mathrm{Tfh}$ responses by controlling IL-2 availability. Nat. Commun. 5, 3495 (2014).

67. Wing, J. B., Ise, W., Kurosaki, T. \& Sakaguchi, S. Regulatory T cells control antigen-specific expansion of $\mathrm{Tfh}$ cell number and humoral immune responses via the coreceptor CTLA-4. Immunity 41, 1013-1025 (2014).

68. Levy, D. N., Aldrovandi, G. M., Kutsch, O. \& Shaw, G. M. Dynamics of HIV-1 recombination in its natural target cells. Proc. Natl Acad. Sci. USA 101, 4204-4209 (2004).

\section{Acknowledgements}

We thank Mario Santiago for valuable discussions and comments. We also thank David Watkins and Nancy Wilson for sharing reagents and animal specimens. MVC (cat \#11580), bicyclam (cat \# 8128) and RAL (cat \# 11680) were obtained through the NIH AIDS reagent program. This work was funded by NIH/NIAID grants R01 AI096966 to E.C. and P.J.S., R01 AI078783A to D.N.L., 5T32AI007447-22 T32 to B.M., T32 5T32AI007447 to M.C., T32 AI007405 to S.M.M. NIH/NHLBI PHS grant HL103286 to T.A., and the Wisconsin National Primate Research Center (WNPRC) P51OD011106. Cell sorting was performed by the University of Colorado Cancer Flow Cytometry
Shared Resource, which is supported by the Cancer Center Support Grant P30CA046934 and the Skin Diseases Research Cores Grant P30AR057212. The funding source played no role in experimental design or data analysis.

\section{Author contributions}

B.M., D.N.L., E.G.R., P.J.S. and E.C. designed the experiments. B.M., S.M.M. and M.C. performed tonsil experiments. B.M., J.M.F., A.K., A.L.M., T.A. and M.D.M performed human lymph node experiments. B.M., J.M.F., E.G.R., P.J.S. and E.C. designed and performed rhesus macaque experiments. B.M. and E.C. wrote the manuscript.

\section{Additional information}

Supplementary Information accompanies this paper at http://www.nature.com/ naturecommunications

Competing financial interests: The authors declare no competing financial interests.

Reprints and permission information is available online at http://npg.nature.com/ reprintsandpermissions/

How to cite this article: Miles, B. et al. Follicular regulatory T cells impair follicular T helper cells in HIV and SIV infection. Nat. Commun. 6:8608 doi: 10.1038/ncomms9608 (2015).

(c) (i) This work is licensed under a Creative Commons Attribution 4.0 International License. The images or other third party material in this article are included in the article's Creative Commons license, unless indicated otherwise in the credit line; if the material is not included under the Creative Commons license, users will need to obtain permission from the license holder to reproduce the material. To view a copy of this license, visit http://creativecommons.org/licenses/by/4.0/ 